\title{
Electrospray Ionization and Triple Quadrupole Tandem Mass Spectrometry Study of Some Biologically Relevant Homo- and Heterodimeric Cadmium Thiolate Conjugates
}

\author{
Federico Maria Rubino, Marco Pitton, Gabri Brambilla, \\ and Antonio Colombi \\ Laboratory for Analytical Toxicology and Metabolomics, Department of Occupational Medicine, Università \\ degli Studi di Milano at Ospedale San Paolo, Milano, Italy
}

A series of 19 compounds of general formula $\mathrm{R}_{1} \mathrm{~S}-\mathrm{Cd}-\mathrm{SR}_{2}, \mathrm{R}_{1}$, and $\mathrm{R}_{2}$, being some biologically relevant thiol amino acids and peptides, were prepared by direct reaction of cadmium(II) ions and thiols in water at millimolar concentration. The obtained products were characterized by electrospray ionization and triple quadrupole tandem mass spectrometry. The source spectra of stoichiometric 1:2 Cd-thiol systems containing either an individual thiol or equimolar mixtures of two different thiols featured several Cd-containing signals, although at much lesser intensity than in the previously reported experiments with mercury(II) (J. Am. Soc. Mass Spectrom. 2004, 15, 288-300). Also, the relative intensity of the homo- and heterodimeric thiolates were significantly different from the theoretically expected 1:2:1 ratio, thus pointing at some degree of discrimination between the different thiols. In particular, homo-cysteine showed much less reactivity than cysteine, and penicillamine and cysteine methyl ester much less than the free amino acid. The fragment spectra show structure-specific ions for the different ligands bound to the metal ion and allow a stand-alone determination of the connectivity also of isomeric pairs. The fragmentation pathways are similar to those observed for the corresponding mercury(II) analogues, with the addition of further intense and specific fragments, one formally carrying a Cd-bound $\mathrm{OH}$ ligand and one connected as a fivemembered oxazolone carrying a cadmium-bis-thiolate side chain, both formed with a high intensity. Energy-resolved fragmentation data show that metal-free ions can be generated from cysteine but not from glutathione conjugates and point to the possibility of unveiling differences in the biochemical behavior of the conjugates of different heavy metals through the detailed study of their mass spectrometric fragmentation. (J Am Soc Mass Spectrom 2006, 17, 1442-1455) (c) 2006 American Society for Mass Spectrometry

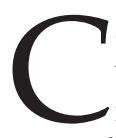
admium is a metal of industrial importance which is mainly employed in metal electroplating, in the manufacture of $\mathrm{Ni}-\mathrm{Cd}$ electric batteries and of electronic materials, such as crystalline cadmium sulphide (CdS), one light-sensing element in measurement devices. Due to its natural and anthropogenic ubiquitous dispersion in the environment, cadmium can be absorbed and stored in the tissue of several plants, also of human food or nonalimentary importance such as rice and tobacco and, thus, be ingested or inhaled by the general population. As several other heavy metals, it has a long-known toxicity, directed towards several body targets, among which are kidney, bone, the immune system, and is also a human carcinogen [1].

Published online July 26, 2006

Address reprint requests to Dr. F. M. Rubino, Laboratory for Analytical Toxicology and Metabolomics, Department of Occupational Medicine, Università degli Studi di Milano at Ospedale San Paolo, v. A di Rudinì 8, I-20142 Milano, Italy. E-mail: Federico.Rubino@unimi.it
One peculiar adverse health effect of cadmium is irreversible loss of the sense of olfaction in workers exposed to aerosols [2]. It has recently been demonstrated that salt solutions of cadmium and zinc, instilled into the nostrils of experimental animal models, are retrogradely transported into the cellular body of olfactory neurons as conjugates of glutathione and of metallothionein [3-7].

Thiol compounds of $\mathrm{Cd}^{2+}$ with glutathione, cysteine, and other biothiols have been identified as excreted biliary metabolites of the metal $[8,9]$ and as its renal transport form across cellular membranes, since the conjugates mimic the shape and charge distribution of natural chemicals, such as cystine, and employ their natural transport systems to migrate between body compartments [10].

The formation equilibria of glutathione and cysteine complexes with cadmium in aqueous solution have been the subject of studies with potentiometry [11], polarography [12, 13], and NMR spectroscopy [14, 15]. 
Conjugates of cadmium and glutathione of 1:1 and 1:2 stoichiometry were identified by radiochemical methods and by MALDI mass spectrometry in the $S$. cerevisiae yeast [16]. The conjugates of phytochelatin, a cysteine-containing plant polypeptide with a strong binding capacity towards heavy metals with cadmium and arsenic have been recently characterized by mass spectrometry and fragment ion analysis [17a, b]. The reactivity of several heavy metal ions towards glutathione and thiol amino acids has been studied by electrospray ionization and mass spectrometry [18, 19]. A theoretical study has recently been devoted to the interaction of cysteine and some divalent metals, among which is cadmium [20].

In the view of probing the reactivity of $\mathrm{Cd}^{2+}$ towards bio-thiols, we have characterized by electrospray ionization and low-energy collisional spectroscopy several compounds of general formula $R_{1} S-C d-S R_{2}\left(R_{1}\right.$ being equal or different from $R_{2}$ ), which are formed in the reaction of $\mathrm{Cd}^{2+}$ with the amino acids and peptides of the glutathione metaboloma and some related drugs. This work is preliminary to the setup of molecularspecific analytical methods to measure the in vitro equilibria of cadmium under biomimetic conditions and in the biological fluids of human subjects exposed either occupationally or through environmental sources.

\section{Experimental}

Caution: Cadmium compounds are hazardous and should be handled with proper precautions, under a fume hood.

All reagents and solvents were of analytical or reagent grade and were employed as received. The employed thiols: cysteine (CySH), cysteine methyl ester (MeOCySH), homo-cysteine $(h \mathrm{CySH})$, penicillamine (PenSH), N-acetylcysteine (NACySH), N-acetyl-penicillamine (NAPenSH), and glutathione (GSH) were supplied by Sigma-Aldrich (Milano, Italy).

Homo- and heterodimeric cadmium(II)-thiol conjugates were prepared by reacting $0.02 \mathrm{M} \mathrm{Cd}$ (II) nitrate with two equivalents of the considered thiols (0.02-0.04 $\mathrm{M})$ in deionized water. These compounds were not isolated, and their fragment spectra were directly recorded from a dilution of the reaction mixture with the ESI diluent, a 1:1 vol/vol water-acetonitrile mixture, containing $0.1 \%$ by volume of formic acid. The solution was admitted into the mass spectrometer source at a rate of $10 \mu \mathrm{L} / \mathrm{min}$ with a Hamilton syringe pump.

Mass spectrometric analyses were performed on an Applied Biosystems API365 triple quadrupole instrument (Monza, Italy), equipped with an ESI source and operated in the positive-ion mode. The orifice and ring potentials were optimized either to minimize in-source fragmentation of some compounds (typical values were $\mathrm{OR}=15 \mathrm{~V}$ and $\mathrm{RNG}=150 \mathrm{~V}$ or $\mathrm{OR}=5 \mathrm{~V}$ and $\mathrm{RNG}=$ $50 \mathrm{~V}$ ) or to purposely generate molecular fragments for further ion analysis (typical values were $\mathrm{OR}=50 \mathrm{~V}$ and $\mathrm{RNG}=350 \mathrm{~V})$.
The source and MS/MS spectra were obtained in the multi-channel average mode over the infusion time of the sample solution until the signal/noise ratio of the relevant signals was judged adequate. Collisionally activated decomposition in MS/MS experiments was accomplished with $\mathrm{N}_{2}$ gas at a pressure setting value (CAD GAS) of 3 and at nominal collision energy values ranging from 2 to $45 \mathrm{~V}$. Acquisition of fragment ions was from $\mathrm{m} / \mathrm{z} 50$ to a value three to five mass units higher than that of the precursor ion.

Unless specified, all $\mathrm{m} / \mathrm{z}$ signals of Cd-containing species are referred to the ${ }^{114} \mathrm{Cd}$ isotope. Fragment spectra were routinely recorded from precursors containing the naturally occurring ${ }^{114} \mathrm{Cd}$ and ${ }^{112} \mathrm{Cd}$ isotopes, to observe which fragments retain cadmium and shift by the expected \pm 2 mass units (to signify the occurrence of such mass shift, the peaks are sometimes labeled with a horizontal two-pointed arrow $(\leftrightarrow)$ in the reported mass spectra).

Post-acquisition elaboration of the spectra and calculations were performed with custom Microsoft Excel spreadsheets on raw data mass-intensity files exported from the mass spectrometer.

\section{Results}

\section{Formation of Cadmium(II)-Thiol Compounds}

Infusion of reaction mixtures containing $\mathrm{Cd}^{2+}$ (as the nitrate salt) and the considered thiols or thiol mixtures at millimolar concentrations into the ESI source allows the observation of signals corresponding to the protonated molecules of the anticipated adducts, to some specific fragments and to some adducts with the nitrate counter-ion and with the molecules of the organic solvents (methanol, iso-propanol and acetonitrile) employed as modifiers in the spray solution. The 19 obtained homo- and heterodimeric compounds of general formula $\mathrm{R}_{1} \mathrm{~S}-\mathrm{Cd}-\mathrm{SR}_{2}$ are listed and numbered in Table 1 according to the increasing molecular mass of the $\mathrm{R}_{1} \mathrm{SH}$ and $\mathrm{R}_{2} \mathrm{SH}$ components, the compound with the lower mass being considered as $\mathrm{R}_{1} \mathrm{SH}$.

Figure 1 reports as an example the source spectrum obtained from a stoichiometric mixture of penicillamine (20 mM), N-acetyl-cysteine (20 mM) and cadmium(II) (10 $\mathrm{mM}$ ), incubated for $30 \mathrm{~min}$ at $37^{\circ} \mathrm{C}$ and diluted $1: 10$ with an ESI modifier containing 50\% (vol/vol) isopropyl alcohol and $0.1 \%$ formic acid to a final concentration of $2 \mathrm{mM}$ with respect to initial cadmium concentration just before infusion. Although no systematic study was carried to explore the contribution of source parameters (in particular of the orifice OR and ring RNG potentials) to the nature and abundance of the different cadmium-containing species in the spectra of the examined cadmium-amino acid systems, the obtained spectra are the compromise between collision-induced decomposition of the precursor protonated conjugates to yield the observed fragments (at higher values of orifice and ring potential) and formation of abundant uncharacterized mass spectrometric signals, 
Table 1. Main ions and relative intensity in the MS/MS fragment spectra of protonated Cd(II) conjugates of thiol amino acids and peptides

\begin{tabular}{|c|c|c|c|c|c|}
\hline & $\mathrm{R}_{1}$ & $\mathrm{R}_{2}$ & $\mathrm{MH}^{+\mathrm{a}}$ & $\begin{array}{l}E_{C M} \\
(e V)\end{array}$ & Main fragment ions \\
\hline 1 & $\mathrm{CySH}$ & $\mathrm{CySH}$ & 355 & 1.10 & 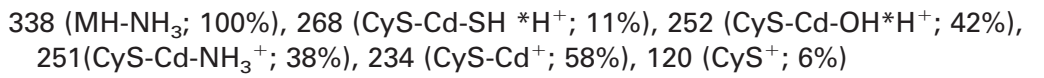 \\
\hline 2 & $\mathrm{CySH}$ & MeOCySH & 369 & 1.20 & $\begin{array}{l}\left.352\left(\mathrm{MH}-\mathrm{NH}_{3} ; 100 \%\right), 266 \text { (MeOCyS-Cd-OH*H }{ }^{+} ; 20 \%\right), 265 \\
\quad\left(\mathrm{MeOCyS}-\mathrm{Cd}-\mathrm{NH}_{3}{ }^{+} ; 20 \%\right), 252\left(\mathrm{CyS}-\mathrm{Cd}-\mathrm{OH}^{*} \mathrm{H}^{+} ; 15 \%\right), 251\left(\mathrm{CyS}-\mathrm{Cd}-\mathrm{NH}_{3}{ }^{+} ;\right. \\
\text {15\%), } 248\left(\mathrm{MeOCyS}^{+} \mathrm{Cd}^{+} ; 75 \%\right), 234\left(\mathrm{CyS}^{+} \mathrm{Cd}^{+} ; 48 \%\right), 136\left(\mathrm{MeOCySH}^{*} \mathrm{H}^{+} ;\right. \\
10 \%), 134\left(\mathrm{MeOCyS}^{+} ; 8 \%\right), 120\left(\mathrm{CyS}^{+} ; 6 \%\right)\end{array}$ \\
\hline 3 & CyS & NACySH & 397 & 1.65 & $\begin{array}{l}379\left(\mathrm{MH}-\mathrm{H}_{2} \mathrm{O} ; 25 \%\right), 362\left(379-\mathrm{NH}_{3} ; 18 \%\right), 334(362-\mathrm{CO} ; 72 \%), 294 \text { (NACyS-Cd- } \\
\left.\mathrm{OH}^{*} \mathrm{H}^{+} ; 34 \%\right) ; 292\left(\mathrm{NACyS}-\mathrm{Cd}-\mathrm{SH}-\mathrm{H}_{2} \mathrm{O}^{*} \mathrm{H}^{+} ; 29 \%\right), 276\left(\mathrm{NACyS}-\mathrm{Cd}^{+} ; 72 \%\right), \\
252\left(\mathrm{CyS}-\mathrm{Cd}-\mathrm{OH}^{*} \mathrm{H}^{+} ; 48 \%\right), 234\left(\mathrm{CyS}-\mathrm{Cd}^{+} ; 100 \%\right), 162\left(\mathrm{NACyS}^{+} ; 66 \%\right), 120 \\
\left(\mathrm{CyS}^{+} ; 35 \%\right)\end{array}$ \\
\hline 4 & CyS & NAPenSH & 425 & 1.55 & 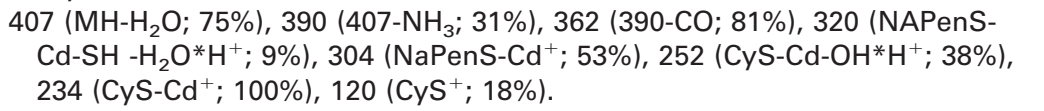 \\
\hline 5 & $\mathrm{CySH}$ & GSH & 541 & 1.18 & 420 (GS-Cd $\left.{ }^{+} ; 53 \%\right), 345$ (420 -Gly; 100\%), 317 (345-CO; 90\%) \\
\hline 6 & $\mathrm{MeOCySH}$ & MeOCySH & 383 & 1.02 & $\begin{array}{l}\left.366\left(\mathrm{MH}_{-} \mathrm{NH}_{3} ; 100 \%\right), 266 \text { (MeOCyS-Cd-OH}{ }^{*} \mathrm{H}^{+} ; 50 \%\right), 265 \\
\left(\mathrm{MeOCyS}-\mathrm{Cd}-\mathrm{NH}_{3}{ }^{+} ; 37 \%\right), 248\left(\mathrm{MeOCyS}-\mathrm{Cd}^{+} ; 100 \%\right), 136\left(\mathrm{MeOCySH}^{*} \mathrm{H}^{+} ;\right. \\
\text {10\%), } 134\left(\mathrm{MeOCyS}^{+} ; 8 \%\right)\end{array}$ \\
\hline 7 & MeOCySH & PenSH & 397 & 0.99 & $\begin{array}{l}380\left(\mathrm{MH}-\mathrm{NH}_{3} ; 100 \%\right), 336\left(\mathrm{MH}-\mathrm{NH}_{3}-\mathrm{CO}_{2} ; 98 \%\right), 282\left(\mathrm{MeOCyS}-\mathrm{Cd}-\mathrm{SH}^{*} \mathrm{H}^{+} ; 5 \%\right) \\
266\left(\mathrm{MeOCyS}-\mathrm{Cd}-\mathrm{OH}^{*} \mathrm{H}^{+} ; 10 \%\right), 265\left(\mathrm{MeOCyS}-\mathrm{Cd}-\mathrm{NH}_{3}^{+} ; 10 \%\right), 248 \\
\left(\mathrm{MeOCyS}-\mathrm{Cd}^{+} ; 75 \%\right), 150\left(\mathrm{PenSH}^{*} \mathrm{H}^{+} ; 10 \%\right)\end{array}$ \\
\hline 8 & hCySh & PenSH & 397 & 1.65 & 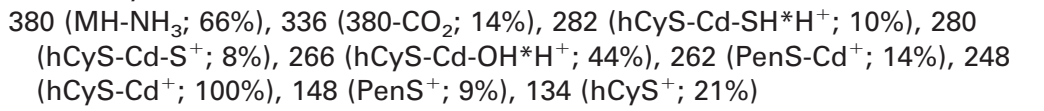 \\
\hline 9 & hCySh & NAPenSH & 439 & 1.50 & $\begin{array}{l}421\left(\mathrm{MH}-\mathrm{H}_{2} \mathrm{O} ; 26 \%\right), 403\left(421-\mathrm{H}_{2} \mathrm{O} ; 6 \%\right), 375(403-\mathrm{CO} ; 19 \%), 320 \text { (NAPenS-Cd- } \\
\left.\qquad \mathrm{SH}-\mathrm{H}_{2} \mathrm{O}^{*} \mathrm{H}^{+} ; 11 \%\right), 304\left(\mathrm{NAPenS}-\mathrm{Cd}^{+} ; 35 \%\right), 286\left(304-\mathrm{H}_{2} \mathrm{O}\right), 266 \text { (hCyS-Cd- } \\
\left.\mathrm{OH}^{*} \mathrm{H}^{+} ; 35 \%\right), 248\left(\mathrm{hCys}-\mathrm{Cd}^{+} ; 100 \%\right), 174(22 \%), 134\left(\mathrm{hCyS}^{+} ; 100 \%\right)\end{array}$ \\
\hline 10 & PenSH & PenSH & 411 & 1.59 & $\begin{array}{l}394\left(\mathrm{MH}-\mathrm{NH}_{3} ; 9 \%\right), 377\left(\mathrm{MH}-\mathrm{CO}_{2} ; 3 \%\right), 350\left(394-\mathrm{CO}_{2} ; 56 \%\right), 333\left(350-\mathrm{NH}_{3} ;\right. \\
\quad 28 \%), 296\left(\mathrm{PenS}-\mathrm{Cd}-\mathrm{SH}^{*} \mathrm{H}^{+} ; 4 \%\right), 289\left(333-\mathrm{CO}_{2} ; 16 \%\right), 280(\mathrm{PenS}-\mathrm{Cd}-\mathrm{OH} \\
\left.\quad{ }^{*} \mathrm{H}^{+} ; 84 \%\right), 262\left(\mathrm{PenS}-\mathrm{Cd}^{+} ; 100 \%\right), 201(350-\mathrm{PenSH} ; 6 \%), 148\left(\mathrm{PenS}^{+} ; 19 \%\right), \\
\quad 116\left(\mathrm{H}_{2} \mathrm{~N}-\mathrm{CH}\left({ }^{+} \mathrm{CMe}_{2}\right)-\mathrm{COOH} ; 3 \%\right)\end{array}$ \\
\hline 11 & PenSH & NACySH & 425 & 2.16 & $\begin{array}{l}294\left(\text { NACyS-Cd-OH }{ }^{*} \mathrm{H}^{+} ; 8 \%\right), 276\left(\text { NACyS}-\mathrm{Cd}^{+} ; 28 \%\right), 262\left(\text { PenS-Cd }^{+} ; 9 \%\right) \\
\quad 162\left(\mathrm{NACyS}^{+} ; 100 \%\right)\end{array}$ \\
\hline 12 & PenSH & NAPenSH & 453 & 1.75 & $\begin{array}{l}435\left(\mathrm{MH}-\mathrm{H}_{2} \mathrm{O} ; 9 \%\right), 418\left(435-\mathrm{NH}_{3} ; 3 \%\right), 374\left(418-\mathrm{CO}_{2} ; 97 \%\right), 320 \text { (NAPenS-Cd- } \\
\left.\mathrm{SH}-\mathrm{H}_{2} \mathrm{O}^{*} \mathrm{H}^{+} ; 31 \%\right), 304\left(\mathrm{NAPenS}-\mathrm{Cd}^{+} ; 100 \%\right), 296(\text { PenS-Cd-SH*H } \\
\end{array}$ \\
\hline 13 & PenSH & $\mathrm{GSH}$ & 569 & 1.17 & $\begin{array}{l}454\left(\mathrm{GS}-\mathrm{Cd}-\mathrm{SH}^{*} \mathrm{H}^{+} ; 4 \%\right), 420\left(\mathrm{GS}-\mathrm{Cd}^{+} ; 100 \%\right), 402\left(420-\mathrm{H}_{2} \mathrm{O} ; 3 \%\right), 345 \text { (GS- } \\
\left.\mathrm{Cd}^{+} \text {-Gly; } 14 \%\right), 317(345-\mathrm{CO} ; 6 \%)\end{array}$ \\
\hline \multirow[t]{2}{*}{14} & $\mathrm{NaCySH}$ & $\mathrm{NaCySH}$ & 439 & 1.44 & $\begin{array}{l}421\left(\mathrm{MH}-\mathrm{H}_{2} \mathrm{O} ; 11 \%\right), 403\left(421-\mathrm{H}_{2} \mathrm{O} ; 3 \%\right), 375(403-\mathrm{CO} ; 9 \%), 333\left(375-\mathrm{CH}_{2}=\mathrm{CO} ;\right. \\
65 \%), 318\left(\mathrm{MH}-\mathrm{CySH}{ }^{*} \mathrm{H}^{+} ; 72 \%\right), 294\left(\mathrm{NACyS}-\mathrm{Cd}-\mathrm{OH}^{*} \mathrm{H}^{+} ; 56 \%\right), 292 \\
\left(\mathrm{NACyS}-\mathrm{Cd}-\mathrm{SH}-\mathrm{H}_{2} \mathrm{O}{ }^{*} \mathrm{H}^{+} ; 89 \%\right), 276\left(\mathrm{NACyS}-\mathrm{Cd}^{+} ; 100 \%\right), 162\left(\mathrm{NACyS}^{+} ;\right. \\
63 \%)\end{array}$ \\
\hline & $\mathrm{NaCySH}$ & - & $276^{b}$ & 1.38 & $258\left(276-\mathrm{H}_{2} \mathrm{O} ; 20 \%\right), 248(276-\mathrm{CO} ; 13 \%), 162\left(\mathrm{NaCyS}^{+} ; 100 \%\right)$ \\
\hline 15 & $\mathrm{NaCySH}$ & $\mathrm{NaPenSH}$ & 467 & 1.70 & $\begin{array}{l}449\left(\mathrm{MH}-\mathrm{H}_{2} \mathrm{O} ; 39 \%\right), 431\left(449-\mathrm{H}_{2} \mathrm{O} ; 4 \%\right), 361\left(403-\mathrm{CH}_{2}=\mathrm{CO} ; 14 \%\right), 346(? ; \\
\left.100 \%), 320\left(\mathrm{NAPenS}-\mathrm{Cd}-\mathrm{SH}-\mathrm{H}_{2} \mathrm{O}{ }^{*} \mathrm{H}^{+} ; 32 \%\right), 304 \text { (NAPenS-Cd } ; 54 \%\right), 292 \\
\left(\mathrm{NACyS}-\mathrm{Cd}-\mathrm{SH}-\mathrm{H}_{2} \mathrm{O} \mathrm{O}^{+} \mathrm{H}^{+} ; 32 \%\right), 286\left(304-\mathrm{H}_{2} \mathrm{O} ; 60 \%\right), 276\left(\mathrm{NACyS}^{+} \mathrm{Cd}^{+} ;\right. \\
69 \%), 262\left(304-\mathrm{CH}_{2}=\mathrm{CO} ; 43 \%\right), 260\left(304-\mathrm{CO}_{2} ; 37 \%\right), 162\left(\mathrm{NACyS}^{+} ; 72 \%\right)\end{array}$ \\
\hline 16 & NACySH & $\mathrm{GSH}$ & 583 & 1.15 & $\begin{array}{l}454\left(\mathrm{GS}-\mathrm{Cd}-\mathrm{SH}{ }^{*} \mathrm{H}^{+} ; 3 \%\right), 420\left(\mathrm{GS}-\mathrm{Cd}^{+} ; 100 \%\right), 402\left(420-\mathrm{H}_{2} \mathrm{O} ; 4 \%\right), 345(402 \\
\quad-\text { Gly; } 22 \%), 317(345-\mathrm{CO} ; 13 \%)\end{array}$ \\
\hline 17 & NAPenSH & NAPenSH & 495 & 1.34 & $\begin{array}{l}477\left(\mathrm{MH}-\mathrm{H}_{2} \mathrm{O} ; 100 \%\right), 403\left(477-\mathrm{CH}_{2}=\mathrm{CO} ; 51 \%\right), 346(? ; 48 \%), 320 \text { (NAPenS-Cd- } \\
\left.\mathrm{SH}-\mathrm{H}_{2} \mathrm{O}^{*} \mathrm{H}^{+} ; 100 \%\right), 304\left(\mathrm{NAPenS}-\mathrm{Cd}^{+} ; 54 \%\right), 286\left(304-\mathrm{H}_{2} \mathrm{O} ; 13 \%\right), 262 \\
\left(304-\mathrm{CH}_{2}=\mathrm{CO} ; 6 \%\right), 260\left(304-\mathrm{CO}_{2} ; 10 \%\right)\end{array}$ \\
\hline \multirow[t]{2}{*}{18} & NAPenSH & - & $304^{b}$ & 1.60 & $286\left(304-\mathrm{H}_{2} \mathrm{O} ; 59 \%\right), 262\left(304-\mathrm{CH}_{2}=\mathrm{CO} ; 100 \%\right), 190\left(\mathrm{NAPenS}^{+} ; 16 \%\right)$ \\
\hline & NAPenSH & GSH & 611 & 0.83 & $593\left(\mathrm{MH}-\mathrm{H}_{2} \mathrm{O} ; 8 \%\right), 454\left(\mathrm{GS}-\mathrm{Cd}-\mathrm{SH}{ }^{*} \mathrm{H}^{+} ; 100 \%\right), 420\left(\mathrm{GS}-\mathrm{Cd}^{+} ; 66 \%\right)$ \\
\hline \multirow[t]{2}{*}{19} & GSH & GSH & 727 & 0.70 & $598(\mathrm{MH}-\mathrm{Pyr} ; 4 \%), 420\left(\mathrm{GS}-\mathrm{Cd}^{+} ; 19 \%\right), 308\left(\mathrm{GSH}{ }^{*} \mathrm{H}^{+} ; 8 \%\right)$ \\
\hline & GSH & - & $420^{\mathrm{b}}$ & 0.88 & $402\left(420-\mathrm{H}_{2} \mathrm{O} ; 7 \%\right), 345$ (420 -Gly; 41\%), 317 (345-CO; 31\%) \\
\hline
\end{tabular}

Abbreviations: CySH: cysteine; $\boldsymbol{h C y S H : ~ h o m o - c y s t e i n e ; ~ P e n S H : ~ p e n i c i l l a m i n e ; ~ N A C y S H : ~} \mathrm{N}$-acetyl-cysteine; NAPenSH: $\mathrm{N}$-acetyl-penicillamine; GSH: glutathione. ${ }^{a}{ }^{114} \mathrm{Cd}$ isotopomer of the molecular cluster, containing the isotopomers $\left[{ }^{112} \mathrm{Cd}-{ }^{-34} \mathrm{~S}\right]$ (approx. $\left.3 \%\right)$ and $\left[{ }^{110} \mathrm{Cd}-{ }^{34} \mathrm{~S}_{2}\right]$ i(approx. $\left.3 \%\right)$. bsource-generated fragment.

possibly due to clusters containing metal ions, ligand amino acids, and solvent molecules (see the signals marked with the asterisk between $\mathrm{m} / \mathrm{z} 500$ and 700 in the reported spectrum). The ESI source parameters were adjusted aiming at stable and intense ion current for recording the MS-MS spectra. 


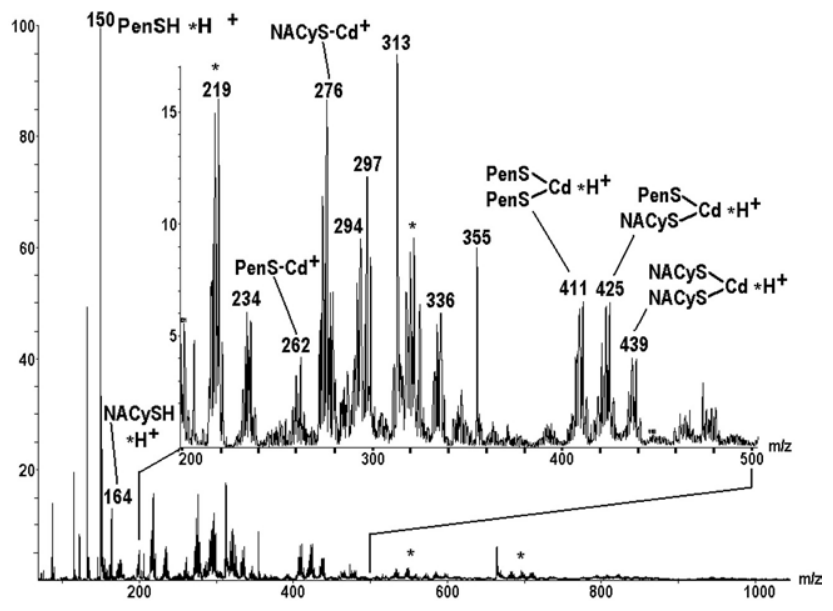

Figure 1. ESI source spectrum of a stoichiometric (1:1:1) mixture of penicillamine, $\mathrm{N}$-acetyl-penicillamine and $\mathrm{Cd}$ (as nitrate), each $2 \mathrm{mM}$, in a 50\% water-isopropyl alcohol mixture containing $0.1 \%$ formic acid (OR potential $15 \mathrm{~V}$; RNG potential $150 \mathrm{~V}$ ). The asterisk marks uncharacterized Cd-containing species.

The reported spectrum shows a prominent signal attributable to protonated penicillamine $(\mathrm{m} / \mathrm{z} 150 ; 100 \%)$, a weaker one due to protonated $N$-acetyl-cysteine $(\mathrm{m} / \mathrm{z} 164$; $11 \%)$, one due to the protonated heterocluster $(\mathrm{m} / \mathrm{z} 313)$. Several cadmium-containing species in the 5 to $15 \%$ relative intensity range, identified because of their characteristic isotopic pattern, can be assigned to the expected cadmium-amino acid conjugates and to their fragments, as confirmed by fragment ion analysis (vide infra), and to some species that may be generated in the source pressure gradient by reaction with molecules of the electrospray solvent during the desolvation step of the ionization process. The main signals are assigned as follows: $m / z 219$ (unidentified); $\mathrm{m} / \mathrm{z} 234$ (CyS-Cd${ }^{+}$, possibly generated from loss of ketene from $m / z$ 276); PenS-Cd ${ }^{+}(m / z$ 262); NAcCyS-Cd ${ }^{+}$( $m / z$ 276); NAcCyS-Cd-OH ${ }^{*} \mathrm{H}^{+}$( $m / z$ 294); $m / z 336$ (NAcCyS-Cd-OiPr*H ${ }^{+}$); $m / z 411$ of the protonated penicillamine-Cd homoconjugate $(\mathbf{1 0}) ; \mathrm{m} / \mathrm{z} 425$ of the heterodimeric $S$-penicillaminyl-S-(N-acetyl)-cysteinylcadmium(II) (11); m/z 439 of the protonated $N$-acetylcysteine homoconjugate (14).

To correctly compare relative signal intensities, to qualitatively appreciate the extent of amino acid conversion to the expected cadmium(II) conjugates, it should be remembered that the ion current of each Cd-containing species is distributed among six main isotopes $\left({ }^{110} \mathrm{Cd}-{ }^{116} \mathrm{Cd}\right)$, the most intense of which, ${ }^{114} \mathrm{Cd}$, only accounts for $29 \%$ of the total. Therefore, the ion current relative to the main $\mathrm{Cd}$ isotopes were summed in the centroided spectra to yield an isotope-merged intensity value for the signals of the $\mathrm{Cd}$-containing species. The intensity ratio of the $\mathrm{Cd}-$ containing species to that of the ligand amino acids in the spectrum of Figure 1 is of approximately 3:1. The intensities of the protonated conjugates of penicillamine $(\mathrm{m} / \mathrm{z}$ $407-413 ; 31 \%)$, of the heterodimeric $S$-penicillaminyl-S( $N$-acetyl)-cysteinyl-cadmium(II) $(\mathrm{m} / \mathrm{z} 421-427 ; 31 \%)$, and of $N$-acetyl-cysteine $(\mathrm{m} / \mathrm{z} 435-441 ; 19 \%)$ show an approximately 1:1:0.5 ratio.
The observed intensity of each detected molecular signal is in principle the result of two phenomena: the chemical conversion efficiency of the ligand amino acid into the conjugate and its detection efficiency, which is related to the degree of analyte protonation and desolvation in the ESI process. When compared with the expected 1:2:1 ratio, which should be observed in the absence of discrimination factors due to differences in the chemical reactivity of the thiol groups of the examined amino acids towards cadmium and of differences in ionization affinity, it may be evaluated that the effect of the $N$-acetyl group on conjugate ionization efficiency weights in the order of a factor of two for the cadmium conjugates, while for the free, protonated amino acids it is higher (approximately eight times, as appreciated from the relative intensities of protonated penicillamine and $N$-acetyl-cysteine in equimolar ratio).

The behavior of the described reaction mixture is representative of most of the examined thiol amino acidcadmium(II) systems, where a substantially higher concentration of the ligand amino acids and of the metal had to be employed to obtain analyzable ion signals than in the corresponding experiments performed on thiol amino acid-mercury(II) systems [21]. It is also worth noting that the relative ratios of the three compounds, as judged by the relative intensities of the signals of their protonated molecules, is quite different from that of the corresponding conjugates of mercury, previously prepared under comparable conditions; in particular, the intensity of the cadmium conjugates of $N$-acetyl-cysteine and of the penicillamine- $N$-acetyl-cysteine heterodimer are much greater than those of the mercury analogs.

For some amino acids, such as homocysteine and for some thiol pairs no signals attributable to formation of the expected conjugates could be observed, while an increase of the concentration of the reagents hampered complete dissolution of the thiol amino acid (as in the case of the poorly soluble $N$-acetyl-penicillamine) or caused precipitation of intractable jelly materials upon mixing of the amino acid and cadmium solutions. In those cases, no effort was made to obtain the products by optimizing the reaction conditions.

\section{Characterization of Protonated bis-Thiolate- Cadmium(II) Species by Tandem} Mass Spectrometry

The protonated molecules of the 19 obtained cadmium(II)bis-thiolates can be characterized by collisional spectroscopy of the ions appearing in the source spectra of the infused mixtures and the main fragments identified in their CAD-MS-MS spectra are listed in Table 2. For several compounds, a range of collision energy values was explored to investigate some details of the fragmentation mechanisms, while a more detailed energy-resolved tandem mass spectrometric study was performed only on protonated bis-cysteinyl-cadmium(II). The spectra reported for each compound in Table 1 have been selected 
as those obtained at a value of the collision energy that yields a large number of fragments spread over the mass range and useful for the identification of Cd-thiol conjugates in biological samples. Examples of conjugates yielding a low or a large number of fragments in the collisionally activated decomposition of their protonated molecules, respectively, are shown in Figure 2 (bisglutathionyl-cadmium(II); 19) and in Figure 3 (S-homocysteinyl-S-(N-acetyl)-penicillaminyl-cadmium(II); 9).

Also, due to the fairly large range of molecular masses of the analyzed ionic precursors, ranging from $\mathrm{m} / \mathrm{z} 274$ of the NACyS ${ }^{112} \mathrm{Cd}^{+}$fragment of protonated (NACyS) ${ }_{2} \mathrm{Cd}$ to $\mathrm{m} / \mathrm{z} 727$ of $\left[{ }^{114} \mathrm{Cd}\right]$-protonated bisglutathionyl-cadmium(II), the values of the collision energy of the reported spectra are referred not to the "laboratory frame" ( $E_{\mathrm{lf}}$, i.e., the nominal collision energy calculated in the employed instrument as the difference between the $\mathrm{Q} 0$ and $\mathrm{R} 02$ potentials), but rather to the center-of-mass $\left(\mathrm{E}_{\mathrm{cm}}\right)$ of the impinging ion-neutral target system, calculated according to eq 1 [22], the mass of the target gas being 28 , that of nitrogen:

$$
\mathrm{E}_{\mathrm{cm}}=\mathrm{E}_{\mathrm{iff}} *\left(\mathrm{~m}_{\mathrm{TAR}} /\left(\mathrm{m}_{\mathrm{TAR}}+\mathrm{m}_{\mathrm{ion}}\right)\right.
$$

The efficiency of the decomposition pathways that give rise to the different fragments within the same molecule or among different molecules may be better appreciated by expressing the intensities of the individual ions as the percent fraction of the total ion current of the collisionally activated fragment spectrum (including the surviving precursor ion), as reported in Table 2, rather than referring to the intensity of the most intense peak in the spectrum, as reported in Table 1.

In general, fragmentation of the analyzed compounds shows a close and expected similarity to that of the corresponding mercury(II) conjugates [21], as well as some unexpected and important differences, due to the appearance of further structurally specific decomposition processes.

Direct fission across the bonds of the C-S-Cd system may formally give rise to four main fragment types, which are coded according to Scheme 1: a nonsulfur containing ion, formally carrying the positive charge on the $\beta$-carbon of the thiol amino acid (a-type fragments); one carrying a formal positive charge on the thiol sulfur atom (b-type fragments), one retaining the cadmium atom in the ionic fragment (c-type), and one formally retaining the entire sulphur-metal-sulphur group in the ionic fragment (d-type). As apparent, b- and c-type ions, as well as a- and $\mathbf{d}$-type ions, give rise to complementary fragment pairs. Moreover, further ionic species with a bis-coordinated cadmium atom carrying one sulphur and one oxygen (coded as $c(\mathrm{OH})$ fragments) ligand may formally derive from c-type ions, although their formation mechanism is still unknown and may be originated by intramolecular or ion-molecule processes (vide infra).

Other fragmentation modes are attributable to the presence of specific functional groups and connectivi- ties, such as the $\alpha$ - and $\gamma$-peptide bonds in the spectra of the glutathione conjugates and the acetyl group of those with $\mathrm{N}$-acetyl-cysteine and $\mathrm{N}$-acetyl-penicillamine ligands, which are separately described.

\section{Fission at the $C-S$ Bonds: Formation of $\boldsymbol{a}$ - and $\boldsymbol{d}$-Type Fragments}

Fragmentation at the $C-S$ bonds to release the $m / z 130$ and 158 a-type fragment ions is not observed in the cadmium(II)-thiol conjugates containing $\mathrm{N}$-acetylcysteine and $\mathrm{N}$-acetyl-penicillamine, respectively, in contradiction of what is observed in the corresponding mercury(II) compounds [21]. Only in the penicillamine homoconjugate 10, a fragment at $\mathrm{m} / \mathrm{z} 116$ (formally an a-type fragment carrying the positive charge at the tertiary $\beta$-carbon, the real connectivity of which was not further investigated, due to its little structural significance) is observed as a weak fragment (1-3\%).

The complementary fragment, formally retaining the intact S-Cd-S connectivity, is observed as the sulfenium (d-type) ion only in conjugate 8 , while as the protonated thiol (dH-type) it is observed in all but three (namely, $\mathbf{5}$ CyS-GSH, 11 Pen-NAPen, 18 GSH-GSH) of the examined compounds, although with a greatly variable abundance $(1-10 \%$ of the total ion current). The most intense fragment $(44 \%)$ is observed in the spectrum of the homodimeric conjugate of $\mathrm{N}$-acetyl-penicillamine and glutathione 18.

Formal loss of water from the $\mathbf{d H}$-type fragments may give rise to fairly intense ions that are observed in the spectra of compounds $3,4,8,9,12,14,15$, and 17 , all but 8 carrying at least one $N$-acetyl residue in the molecular connectivity. In the heterodimeric compounds $3,4,9$, and 12 , all carrying one ligand with a free, protonated amino group and one with an $\mathrm{N}$-acetyl group, only the fragment with the modification is observed; in the heterodimeric conjugate 15 , the ratio of the two possible fragments is of approximately two in favor of that of $\mathrm{N}$-acetyl-penicillamine. A greater intensity of the fragment is observed in compounds 14,15, and 17 , which carry two $\mathrm{N}$-acetyl groups. Its formation from the protonated molecule can be depicted as in Scheme 2, by two parallel pathways, each composed of the same two fragmentation processes occurring one in each thiol amino acid residue.

Fragmentation process a (loss of water) corresponds to the oxazolone-forming pathway, which is the accepted process for fission of the peptide bond of protonated peptides [23] to yield the $\mathbf{b}$-type fragment in Roepstorff and Fohlmann's nomenclature [24]. Fragmentation process $\mathbf{b}$ (formation of the $\mathrm{S}-\mathrm{H}$ bond) can be envisaged as a charge-remote process, yielding the dH-type fragment also observed as a stand-alone, yet weak, peak in the spectra of the examined conjugates.

To investigate the precise order of occurrence of processes $\mathbf{a}$ and $\mathbf{b}$ in the formation of the $\left[\mathrm{dH}-\mathrm{H}_{2} \mathrm{O}\right]^{+}$fragment, the source-generated $\left({ }^{114} \mathrm{Cd}\right)-\left[\mathrm{MH}-\mathrm{H}_{2} \mathrm{O}\right]^{+}$frag- 


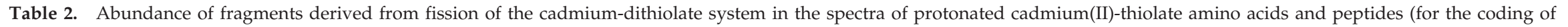
fragments, see text and Scheme 1)

\begin{tabular}{|c|c|c|c|c|c|c|c|c|c|c|c|c|c|c|c|c|c|c|c|c|c|}
\hline & $m / z$ & $\begin{array}{l}E_{c m} \\
(\mathrm{eV})\end{array}$ & $\mathrm{R}_{1} \mathrm{SH}$ & $\mathrm{MH}$ & $a_{1}$ & $\mathrm{~b}_{1}$ & $\mathrm{~b}_{1} \mathrm{H}$ & $\mathrm{c}_{1}$ & $\mathrm{~d}_{1} \mathrm{H}-\mathrm{H}_{2} \mathrm{O}$ & $\mathrm{c}_{1}(\mathrm{OH})$ & $\mathrm{d}_{1}$ & $\mathrm{~d}_{1} \mathrm{H}$ & $\mathrm{d}_{2} \mathrm{H}$ & $d_{2}$ & $\mathrm{c}_{2}(\mathrm{OH})$ & $\mathrm{d}_{2} \mathrm{H}-\mathrm{H}_{2} \mathrm{O}$ & $\mathrm{c}_{2}$ & $b_{2} \mathrm{H}$ & $\mathrm{b}_{2}$ & $a_{2}$ & $\mathrm{R}_{2} \mathrm{SH}$ \\
\hline 1 & 355 & 1.83 & $\mathrm{CySH}$ & 1 & & 13 & & 24 & & 10 & & 1 & 1 & & 10 & & 24 & & 13 & & CySH \\
\hline 2 & 369 & 1.20 & $\mathrm{CySH}$ & 24 & & 6 & & 12 & & 4 & & & & & 5 & & 18 & 2 & 8 & & MeOCySH \\
\hline 3 & 397 & 2.31 & CySH & 0,2 & & 37 & & 11 & & 5 & & & & & 2 & 2 & 4 & & 39 & & NACySH \\
\hline 4 & 425 & 2.16 & CySH & 1 & & 41 & & 27 & & 14 & & & & & & & 3 & & & & NAPenSH \\
\hline 5 & 541 & 1.18 & CySH & 9 & & & & & & & & & & & & & 67 & & & & $\mathrm{GSH}$ \\
\hline 6 & 383 & 1.02 & MeOCySH & 25 & & 1 & 1 & 13 & & 4 & & & & & 4 & & 13 & 1 & 1 & & CySH \\
\hline 7 & 397 & 0.99 & MeOCySH & 25 & & & & 18 & & 2 & 1 & & & & & & & & 2 & & PenSH \\
\hline 8 & 397 & 2.31 & hCySH & 0,3 & & 46 & & 25 & & 10 & 1 & 1 & & & & & 3 & & 12 & & PenSH \\
\hline 9 & 439 & 2.10 & hCySH & 1 & & 47 & & 22 & & 8 & & & & & & 2 & 3 & & & & NAPenSH \\
\hline 10 & 411 & 2.17 & PenSH & 0,2 & & 18 & & 12 & & 11 & & 0,2 & 0,2 & & 11 & & 12 & & 18 & & PenSH \\
\hline 11 & 425 & 2.16 & PenSH & 1 & & & & 6 & & 5 & & & & & & & 19 & & 68 & & NACySH \\
\hline 12 & 453 & 2.04 & PenSH & 0,3 & & 12 & & 19 & & & & 2 & & & & 6 & 15 & & 3 & & NAPenSH \\
\hline 13 & 569 & 1.64 & PenSH & 48 & & & & & & & & & 3 & & & & 29 & & & & GSH \\
\hline 14 & 439 & 2.10 & NACySH & 1 & & 24 & & 2 & 2 & & & & & & & 2 & 2 & & 24 & & NACySH \\
\hline 15 & 467 & 1.98 & NACySH & 0,2 & & 28 & & 10 & 4 & 3 & & & & & & 9 & 6 & & & & NAPenSH \\
\hline 16 & 583 & 1.15 & NACySH & 5 & & & & & & & & & & & & & 68 & & & & $\mathrm{GSH}$ \\
\hline 17 & 495 & 1.34 & NAPenSH & 0,2 & & & & 9 & 16 & & & & & & & 16 & 9 & & & & NAPenSH \\
\hline 18 & 611 & 0.83 & NAPenSH & 23 & & & & & & & & & 44 & & & & 29 & & & & GSH \\
\hline 19 & 727 & 0.70 & $\mathrm{GSH}$ & 76 & & & 3 & 8 & & & & & & & & & 8 & 3 & & & GSH \\
\hline
\end{tabular}

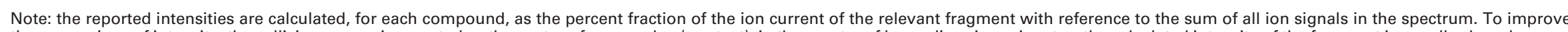

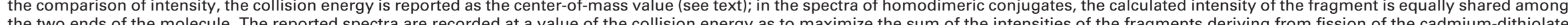

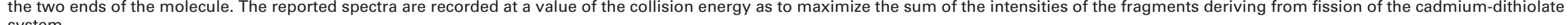
system. 

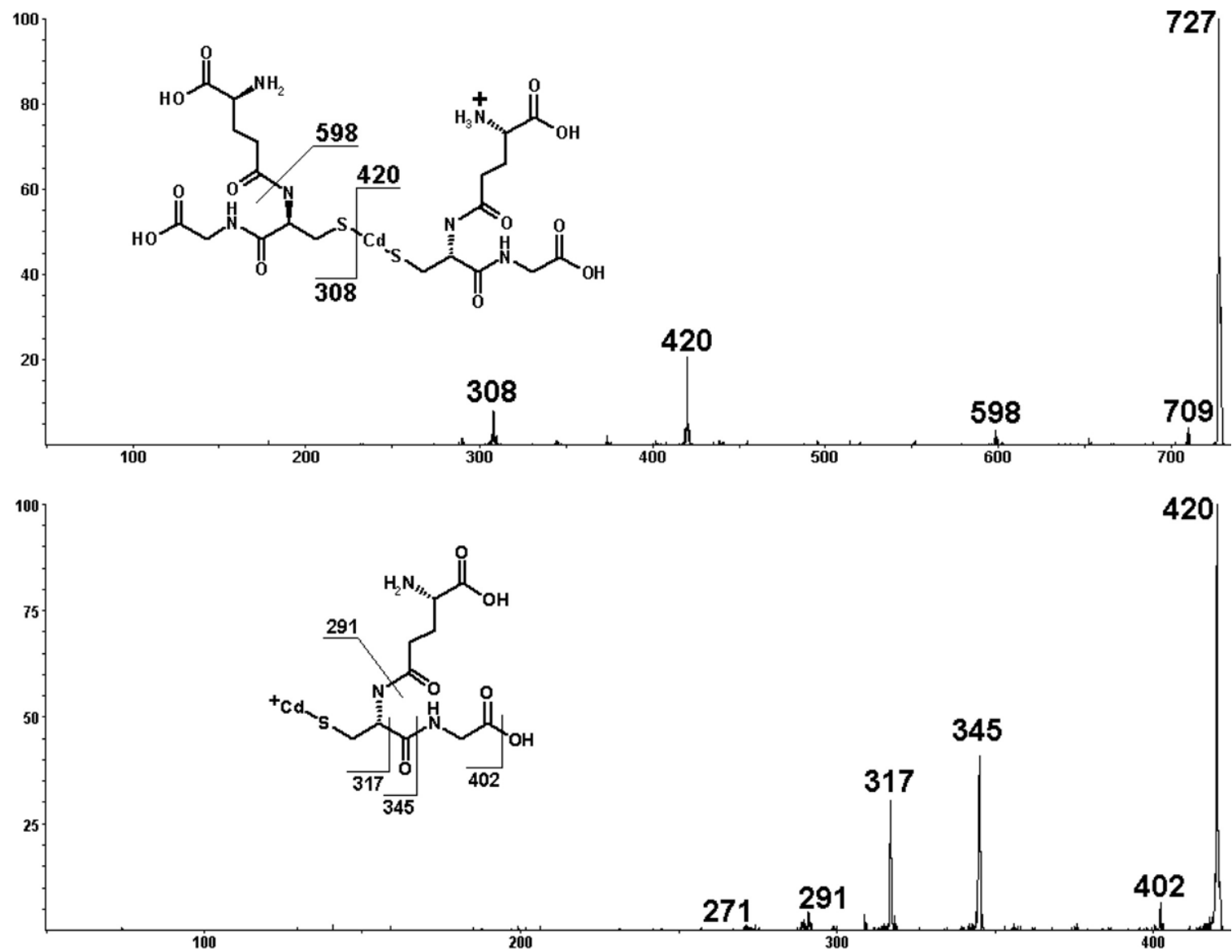

Figure 2. Fragment spectra of: (upper) protonated $\left[{ }^{114} \mathrm{Cd}\right]$-bis-glutathionyl-cadmium(II) at $\mathrm{m} / \mathrm{z} 727$ (collision energy: $0.70 \mathrm{eV}_{\mathrm{CM}}$ ); (lower) $\left[{ }^{114} \mathrm{Cd}\right]$-glutathionyl-cadmium(II) at $\mathrm{m} / \mathrm{z} 420$ (collision energy: $\left.0.88 \mathrm{eV}_{\mathrm{CM}}\right)$.

ments of the conjugates 14 [(NACyS $)_{2} \mathrm{Cd}$ ], 15 (NACyS-CdSPenNA), and 17 [(NAPenS $\left.)_{2} \mathrm{Cd}\right]$ were subjected to fragment ion analysis and showed formation of the product ions at $\mathrm{m} / \mathrm{z} 292$ and 320 as one of the most intense processes. Moreover, absence of the $\mathbf{d H}$-type fragment in the fragment spectra of conjugates $\mathbf{1 4 , 1 5}$, and $\mathbf{1 7}$, where the $\left.\mathbf{d H}-\mathrm{H}_{2} \mathrm{O}\right]^{+}$fragment is particularly intense, may support the hypothesis that the overall pathway leading to this fragment sees the intermediacy of the $\left[\mathrm{MH}-\mathrm{H}_{2} \mathrm{O}\right]^{+}$ fragment rather than that of the dH-type fragment (pathway on the left of Scheme 2).

\section{Fission at the $C d-S$ Bonds: Formation of $\boldsymbol{b}$ - and c-Type Fragments}

Fission at the $\mathrm{Cd}-\mathrm{S}$ bonds generally give rise to intense fragments either retaining (c-type fragments), or not (b-type fragments), the metal in the ionic fragment. These fragments are important not only from the structural point of view, since they allow to confirm the molecular connectivity and to identify the involved thiols, but also from the point of view of the biochemical and toxicological significance of the heavy metalthiol conjugates. In the examined compounds, $\mathbf{b}$-type fragments are comparatively less frequent $(7 / 14$ com- pounds show at least one) and less abundant (2-10\% of the total ion current) than c-type ones (13/14 compounds; $17-55 \%$ of the total ion current).

Other metal-retaining ionic species can be observed in the spectra, which feature a formally bis-coordinated cadmium atom with one amino acid thiolate and one hydroxyl ligand, coded as c(OH)-type fragments. To investigate the connectivity of this new fragment, fragment ion analysis was carried out on a $\mathrm{m} / \mathrm{z} 320\left({ }^{112} \mathrm{Cd}\right) / 322\left({ }^{114} \mathrm{Cd}\right)$ source-generated ion in the spectrum of protonated (NAPenS) ${ }_{2} \mathrm{Cd}$ (17) (Figure 4). It is worth noting that no $\mathrm{Cd}$-free fragment ions are observed even at the relatively high value of the collision energy $\left(1.91 \mathrm{eV}_{\mathrm{cm}}\right)$ employed to enhance the poor fragmentation of the precursor ion observed at lower energy (not shown), except for very low-mass $N$-acetyl-penicillamine fragments at $\mathrm{m} / \mathrm{z} 190$ $\left(\mathrm{NAPenS}^{+}\right.$) and below $\mathrm{m} / \mathrm{z} 150(\mathrm{~m} / \mathrm{z}$ 146;112;102;87;70 [25]. Several Cd-containing fragments are present down to the most intense peak observed at $\mathrm{m} / \mathrm{z} 147 / 149$, which possibly analyzes for $\left[\mathrm{HO}-\mathrm{Cd}-\mathrm{OH} 2^{+}\right]$or for $\left[\mathrm{CdS}^{*} \mathrm{H}^{+}\right]$(the accurate mass could not be measured), thus pointing to a very tight metal binding to the organic ligand and at extensive rearrangement of the binding atoms, which accounts for the formation of many fragments in the spectrum. 


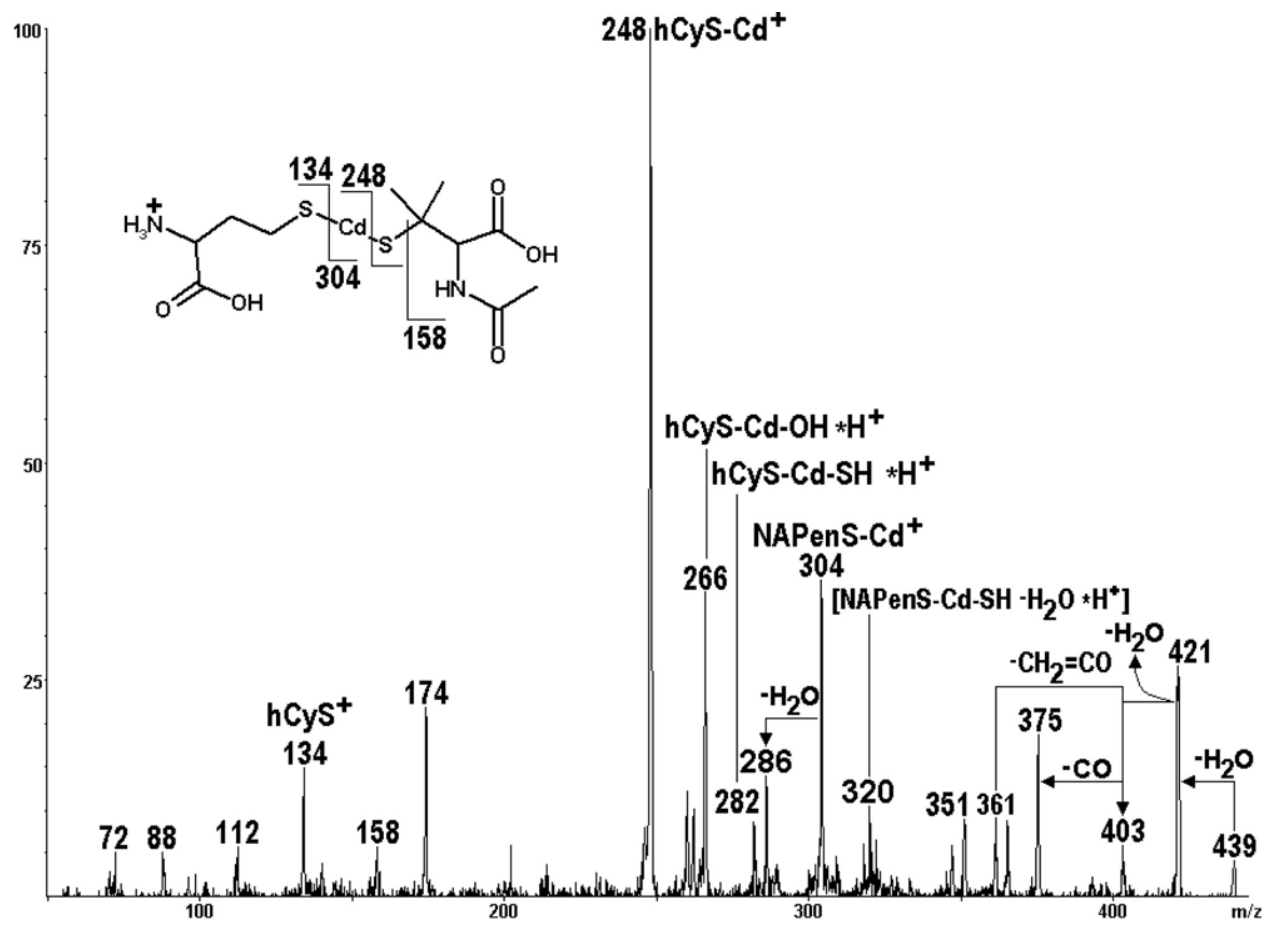

Figure 3. Fragment spectra of protonated $\left[{ }^{114} \mathrm{Cd}\right]-S$-homo-cysteinyl-S-(N-acetyl)-penicillaminyl-cadmium(II) 8 at a collision energy of $1.43 \mathrm{eV}_{\mathrm{cm}}$.

The precursor ion undergoes two consecutive losses of one water molecule from the precursor ion (possibly one from the hydroxyl ligand formally placed on the metal center and one from the carboxyl group through the oxazolidinone pathway of Scheme 2) to yield $\mathrm{m} / \mathrm{z}$ $302 / 304$ and 284/286; further loss of ketene and of the elements of formic acid occurs from $\mathrm{m} / \mathrm{z} 302 / 304$. Occurrence of these fragmentations confirms the integrity of the $\mathrm{N}$-acetyl and of the carboxyl portions of the fragment and suggest that the $c(\mathrm{OH})$-type fragment may be connected as having a hydroxyl ligand at the metal center.

To investigate the mechanism of the reaction leading to the $c(\mathrm{OH})$-type fragment, three model cadmium conjugates of cysteine methyl ester, the homodimeric one $(6 ; m / z 383)$ and the heterodimeric ones of cysteine (2; m/z 369) and of penicillamine $(7 ; \mathrm{m} / \mathrm{z} 397)$ were studied. In their fragment spectra, the ions derived from the cysteine methyl ester part of the protonated precursor molecules are more intense than those of either

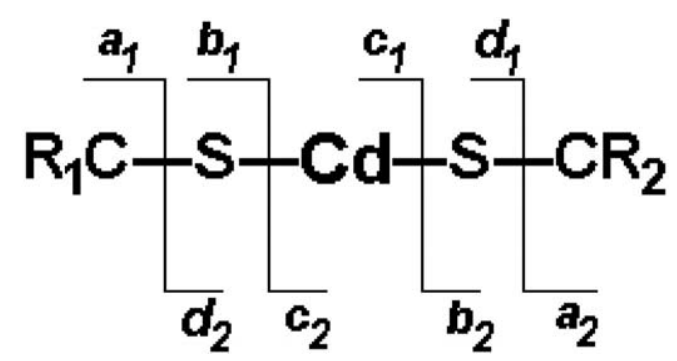

Scheme 1 cysteine or penicillamine (the latter are almost completely missing in the fragment spectra of the penicillamine conjugate) and feature the same pattern (formation of $\mathrm{RS}-\mathrm{Cd}-\mathrm{NH}_{3}^{+}$and $\mathrm{RS}-\mathrm{Cd}-\mathrm{OH}^{*} \mathrm{H}^{+}$species) observed in the cysteine homo-conjugate $\mathbf{1}$, considered as the reference compound. On the contrary, transfer of the methoxyl group of the methyl ester to the (formally) cationic metal center to yield a $\mathrm{m} / \mathrm{z} 280$ fragment is not observed in any of the examined conjugates 2, 6, or 7 . Moreover, the origin of a fragment at $\mathrm{m} / \mathrm{z} 266$ (formally connected as MeOCyS-Cd-OH ${ }^{*} \mathrm{H}^{+}$) among the unimolecular fragments of the protonated homo-conjugate of cysteine methyl ester 2 could not be understood, since its formation from the protonated precursor is hampered by lack of a hydroxyl function. Such fragment may be generated by ion-molecule reaction of the main c-type fragment (e.g., MeOCyS-Cd ${ }^{+}$at $m / z$ 248) with background water either in the interface region of the electrospray source or in the triple quadrupole collision cell. Indeed, both processes may occur in the instrument employed by us, since in the standard operational mode the nitrogen gas employed to fill the collision chamber is taken from the curtain gas supply and may thus contain traces of the electrospray solvents. Recently, this same instrument was employed to purposely perform ion-molecule reactions with selected volatile reagents in either instrument region [25]. This likely explains our observation of several products of RS$\mathrm{Cd}-\mathrm{X}$ stoichiometry ( $\mathrm{R}$ being several thiol amino acids, $X$ being $\mathrm{H}_{2} \mathrm{O}$, iPrOH, and $\mathrm{MeCN}$ ) observed in the source spectra, as exemplified in Figure 1 by $\mathrm{m} / \mathrm{z} 336$ 


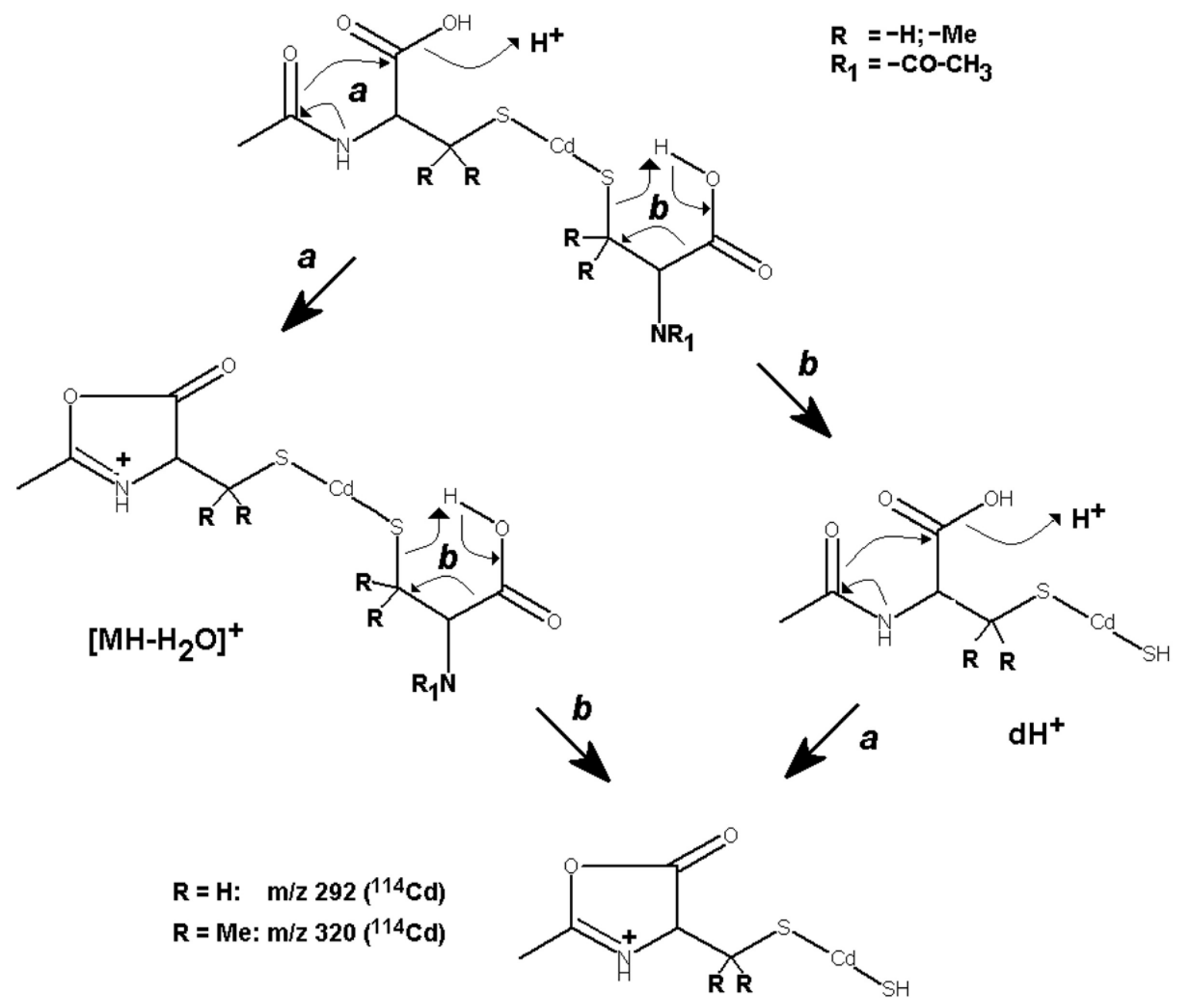

Scheme 2

(NACyS-Cd-OiPr ${ }^{*} \mathrm{H}^{+}$), although the attempt to demonstrate reaction in the source by $\mathrm{D}_{2} \mathrm{O}$ exchange failed to give interpretable results, due to the overlap of the $\mathrm{Cd}$ isotope pattern to those of ion species with a different number of exchanged labile protons. Also, our attempt to investigate the occurrence of ion-molecule reactions with trace water $\left(\right.$ and $\mathrm{D}_{2} \mathrm{O}$ ) in the collision cell [26] (as suggested by one Referee) was frustrated by experimental limitations.

\section{Decomposition of Cadmium(II)-Monothiolate Fragment Ions}

The source spectra of several cadmium-thiol amino acid or peptide systems feature some ions at the $m / z$ values expected for the $\mathrm{RS}-\mathrm{Cd}^{+}$species (c-type fragments). To probe their connectivity, those of $N$-acetyl-cysteine $(\mathrm{m} / \mathrm{z}$ 274/276), of $N$-acetyl-penicillamine $(\mathrm{m} / \mathrm{z} 302 / 304)$, and of glutathione $(\mathrm{m} / \mathrm{z} 418 / 420)$ were subject to fragment ion analysis by collision-activated decomposition at several values of collision energy.

In the case of amino acid and $N$-acetyl-amino acid ligands, release of the metal ion to yield a b-type metal-free ion only requires a mild collisional activation, as apparent from the spectrum of the c-type fragment of $N$-acetyl-cysteine $(m / z 274 / 276)$, reported in Figure 5, which yields the ion at $m / z 162$ as the main fragment (approximately $60 \%$ of the TIC at $1,39 \mathrm{eV}_{\mathrm{cm}}$ ). What is of particular interest in the decomposition of this ion is the occurrence of two parallel processes, one entailing stepwise loss of water and carbon monoxide, the other loss of carbon monoxide from the precursor ion.

Formation of GS-Cd ${ }^{+}$ions from the protonated precursors of their homo- and heterodimeric conjugates and decomposition through loss of the coordinated metal is an important process from the point of view of the toxicological significance of the heavy metal-thiol conjugates. Although a detailed energy-resolved study of formation and decomposition of these species is outside the scope of this particular work, preliminary data obtained on compounds 5, 13, 16, 18 and 19 show that all compounds yield the GS-Cd ${ }^{+}$fragment with comparable efficiency from the respective protonated precursor ions. Fragmentation of the glutathionyl-cadmium(II) ion only features loss of water from the 

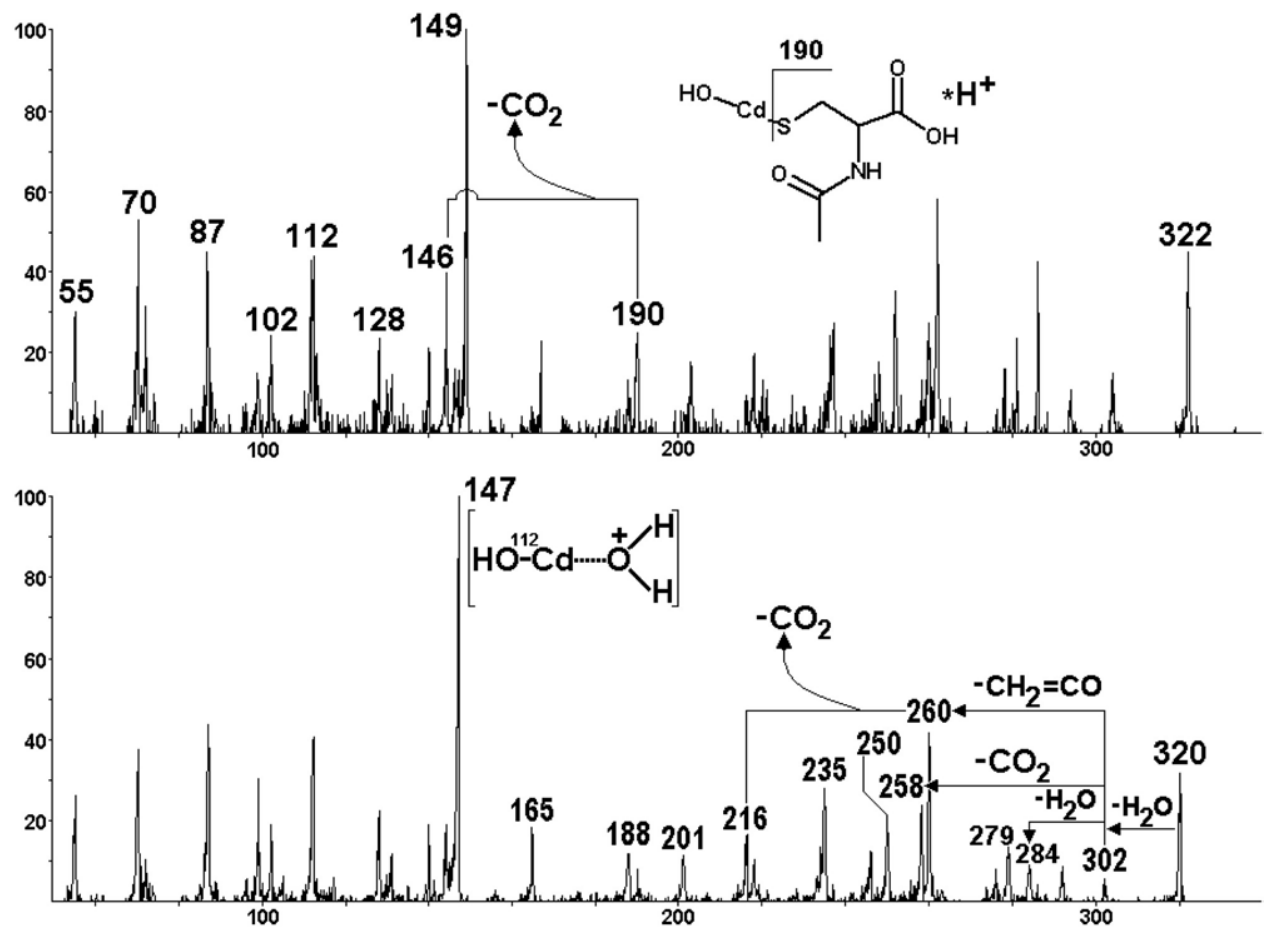

147

Figure 4. Fragment spectra of the source-generated fragment $\left[{ }^{114} \mathrm{Cd}\right]-$ (upper panel) and $\left[{ }^{112} \mathrm{Cd}\right]-$ NAPenS-Cd-OH ${ }^{*} \mathrm{H}^{+}$(lower panel) at a collision energy of $1.91 \mathrm{eV}_{\mathrm{CM}}$.

$\gamma$-glutamyl $\mathrm{N}$-terminus, as well as that of glycine to yield the cysteine acylium and immonium ions $\left(a_{2}\right.$ and $b_{2}$ ions in Roepstorff and Fohlmann's nomenclature [24], but no Cd-free fragment at collision energies up to
$1.8 \mathrm{eV}_{\mathrm{cm}}$, as also reported by Burford et al. [19]. Two carboxyl groups (one from the glycine C-terminus, the other from glutamic acid) of which at least one in the deprotonated form may coordinate the cadmium ion in

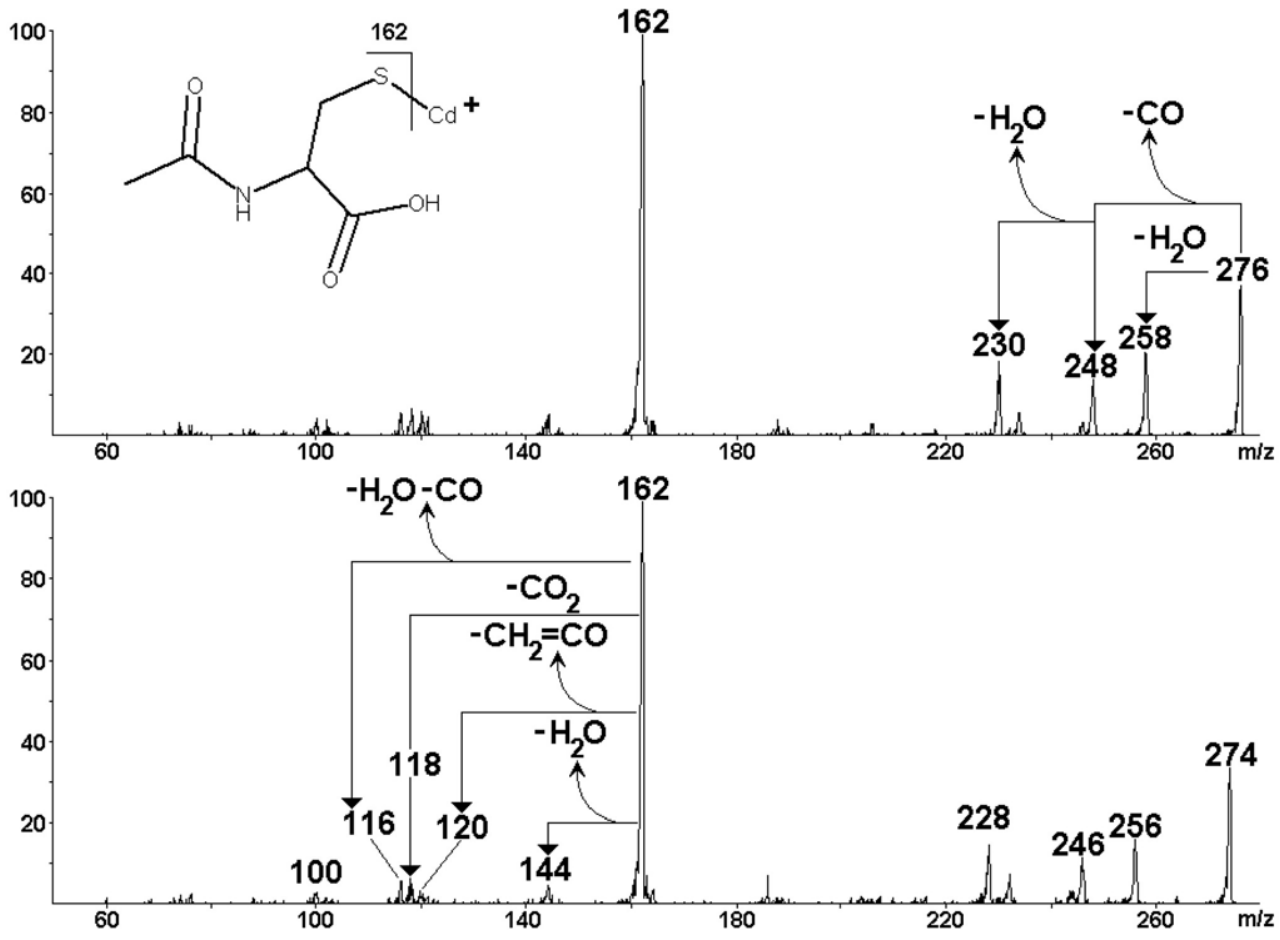

Figure 5. Fragment spectra of the source-generated fragment $\left[{ }^{114} \mathrm{Cd}\right]-$ (upper panel) and $\left[{ }^{112} \mathrm{Cd}\right]-$ NACyS-Cd ${ }^{+}$(lower panel) at a collision energy of $1.39 \mathrm{eV}_{\mathrm{CM}}$. 


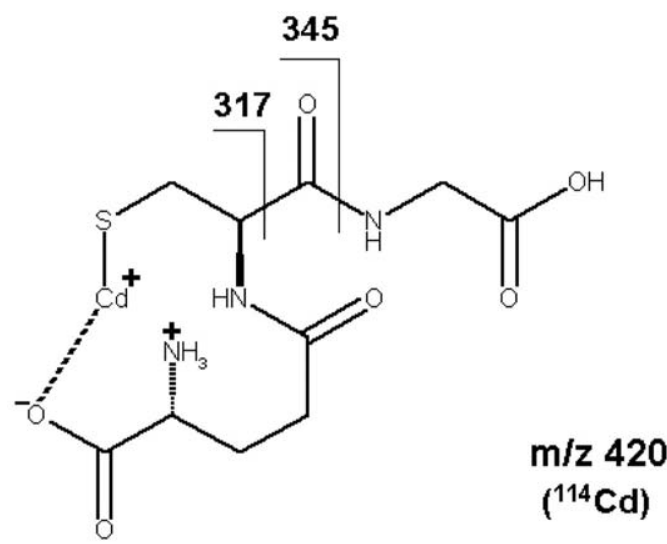

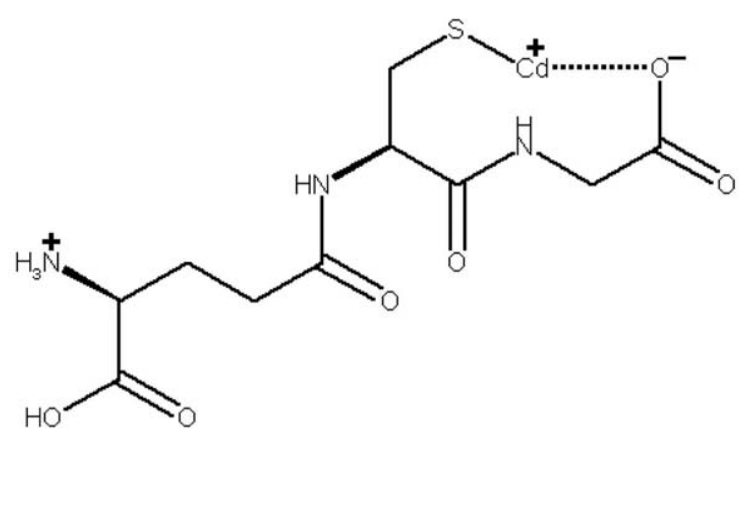

Scheme 3

a macrocyclic connectivity, as depicted in Scheme 3. Since loss of the $N$-terminal $\gamma$-glutamyl residue (either as the $m / z 130$ protonated pyroglutamic acid or as the loss of $129 \mathrm{u}$ ) is suppressed, it is likely its carboxyl group, rather than that of glycine, to coordinate the metal atom.

\section{Protonated Amino Acid and Peptide Ions}

The only fragment corresponding to a protonated thiol amino acids or peptide ( $\mathrm{RSH}^{*} \mathrm{H}^{+} ; b \mathrm{H}$-type fragment) observed in the spectra of cadmium(II)-thiolates is that of protonated glutathione $(\mathrm{m} / \mathrm{z} 308)$ occurring in the symmetrical conjugate but not in any of the other examined heterodimeric conjugates.

\section{Fragments from Other Functional Groups}

The amino acid and $\mathrm{N}$-acetyl amino acid functions of the participating thiols give rise to their own fragmentation processes, which may account for an abundant proportion of the ion current. All conjugates undergo concerted loss of water and carbon monoxide from the amino and carboxyl group(s), single or double stepwise loss of water, and those carrying free amino groups also give rise to single or double stepwise loss of ammonia. A few compounds containing penicillamine also undergo loss of the carboxyl group as carbon dioxide. Some conjugates containing $\mathrm{N}$-acetyl-cysteine and $\mathrm{N}$ acetyl-penicillamine also undergo loss of the acetyl group as a formal neutral ketene, setting the amino group in the free form and thus triggering further fragmentation.

Parallel losses of water and of ammonia occur from the two thiol components in the isomeric conjugate pair of protonated $S$-cysteinyl-S-(N-acetyl)penicillaminyl-cadmium(II) (4) and $S$-penicillaminyl$\mathrm{S}$-(N-acetyl)-cysteinyl-cadmium(II) (11). The [MH $\left.\mathrm{NH}_{3}\right]^{+} /\left[\mathrm{MH}-\mathrm{H}_{2} \mathrm{O}\right]^{+}$ion ratio is much lower in the penicillamine conjugate than in the cysteine one. The difference can be explained since water loss occurs through the oxazolone pathway (Scheme 2), while loss of ammonia occurs by intramolecular nucleophilic displacement yielding the thiiranecarboxylic unit (Scheme 4). While the steric hindrance of the gem-dimethyl group of penicillamine is not relevant to the generation of the $\left[\mathrm{MH}-\mathrm{H}_{2} \mathrm{O}\right]^{+}$ion, since it is far from the reacting center, it hampers formation of the thiirane ring in the process leading to the $[\mathrm{MH}-$ $\left.\mathrm{NH}_{3}\right]^{+}$fragment.

\section{Unimolecular Decomposition \\ of bis-Cysteinyl-Cadmium(II)}

A peculiar difference in the fragment spectrum of protonated bis-cisteinyl-cadmium(II) $\mathbf{1}$ among all examined cadmium conjugates is occurrence of a formal $c\left(\mathrm{NH}_{2}\right)$ fragment is observed $(\mathrm{m} / \mathrm{z} 249 / 251)$ only in the same range of collision energy where the $\left[\mathrm{M}-\mathrm{NH}_{3}\right]^{+}$ fragment appears and which is not observed as a collision-induced dissociation product in the ion source. It is conceivable that the ion-neutral complex generated by intramolecular nucleophilic displacement of the protonated amino group may either dissociate to yield the $\left[\mathrm{MH}-\mathrm{NH}_{3}\right]^{+}$ion or generate the fragment at $\mathrm{m} / \mathrm{z}$ $249 / 251$ through nucleophilic displacement of the thiiranecarboxylic acid neutral, as depicted in Scheme 4 (vide infra).

To support this hypothesis and to gain insight in the several problems arising in the mechanistic interpretation of the fragmentation of Cd-thiolates, a more detailed energy-resolved fragment ion analysis was obtained for this most simple model compound. The experiments were performed on the ${ }^{110} \mathrm{Cd}$ isotopomer at $m / z 351$, which contains the lightest abundant isotope of cadmium, to minimize the contribution of ${ }^{13} \mathrm{C}$ and ${ }^{34} \mathrm{~S}$ from the other isotopomers of the molecular envelope. The relative abundance of the nine main fragments and of the protonated molecule are plotted versus the center-of-mass collision energy in the range of approximately 0.1 to $3.0 \mathrm{eV}_{\mathrm{CM}}$ (from 1 to $40 \mathrm{~V}$ of nominal collision energy), as reported in Figure $6 a$ and $b$.

Only two fragments, i.e., the $\mathbf{b}$ - and $\mathbf{b} H$-type frag- 
<smiles>NC(CS[CH]SC[C@H](N)C(=O)O)C(=O)O</smiles>

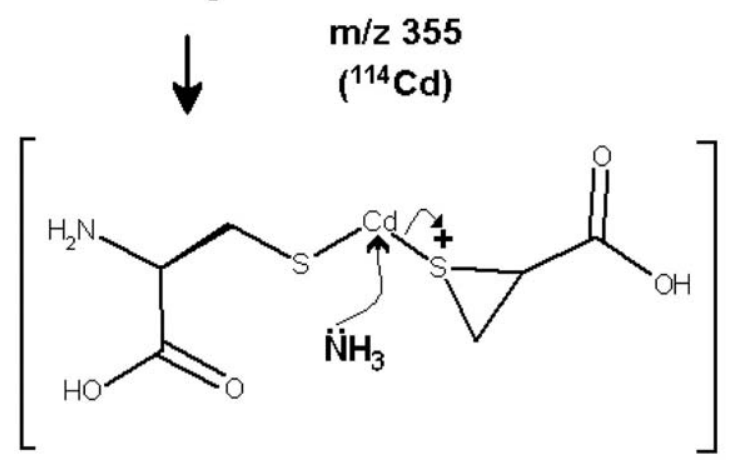<smiles>NC(CS[CH][NH3+])C(=O)O</smiles>

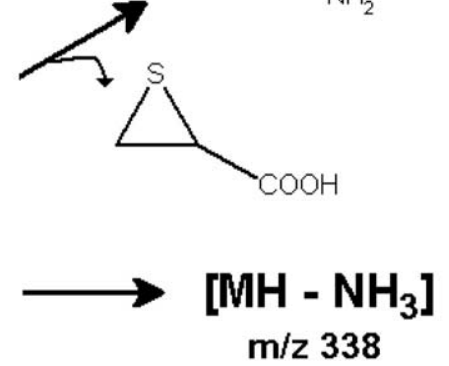

$\mathrm{m} / \mathrm{z} 251$

Scheme 4

ments show a steady increase with the increasing range of collision energy, while the relative yields of all other fragments maximize between approximately 1 and 2.5 $\mathrm{eV}_{\mathrm{cm}}$ and then decrease. The value of energy at which the maximum yield of the fragment occurs may be employed to evaluate the relative ease of formation of the fragments deriving from nominal direct fission of the cadmium thiolate bond system or from metathesis reactions and to judge whether lower $\mathrm{m} / \mathrm{z}$ fragments may really derive from higher $\mathrm{m} / \mathrm{z}$ ones by loss of chemically meaningful neutrals. To this aim, a preliminary evaluation of the maxima was calculated from the first derivative of the curves, as reported in Table 3.

In particular, the yield of the $\left[\mathrm{MH}-\mathrm{NH}_{3}\right]^{+}$and CyS-Cd- $\mathrm{NH}_{2}{ }^{*} \mathrm{H}^{+}$fragments maximize at a very close value of approximately $1.3 \mathrm{eV}_{\mathrm{cm}}$ and decrease with almost parallel curves, thus strengthening the probability of the mechanism of Scheme 4, which is closely similar to the behavior observed for protonated cysteine [28], cystine [27], and bis-cysteinyl-mercury(II) [21], and thoroughly characterized by computational methods for cysteine [28a, b]. Also, the close values of the energy maxima of the species connected as $\left[\mathrm{CyS}-\mathrm{Cd}-\mathrm{X}^{*} \mathrm{H}^{+}\right], \mathrm{X}$ being $\mathrm{NH}_{2}$ and $\mathrm{SH}$ and the higher value for that bearing the $\mathrm{X}$ ligand as $\mathrm{OH}$ suggest that the isomerization of the molecular connectivity to yield the $\mathbf{c}(\mathbf{O H})$ structure is a higher-energy process than the $\mathrm{N} \rightarrow \mathrm{S}$ metathesis leading to the CyS-Cd- $-\mathrm{NH}_{2}{ }^{*} \mathrm{H}^{+}$fragment and than the capture of the hydroxyl proton to yield the $\mathbf{d H}$ fragment. Moreover, the large energy difference $(>1.2 \mathrm{eV})$ between the CyS-Cd ${ }^{+}$and $\mathrm{CyS}^{+}$fragments points to a relatively energetic requirement for detachment of the $\mathrm{Cd}$ atom from the thiolate ligand, through a formal reduction of the metal from $\mathrm{Cd}^{2+}$ to $\mathrm{Cd}$ [0] in the cysteinyl-cadmium(II) species.

The fragmentation efficiency curves for the corre-
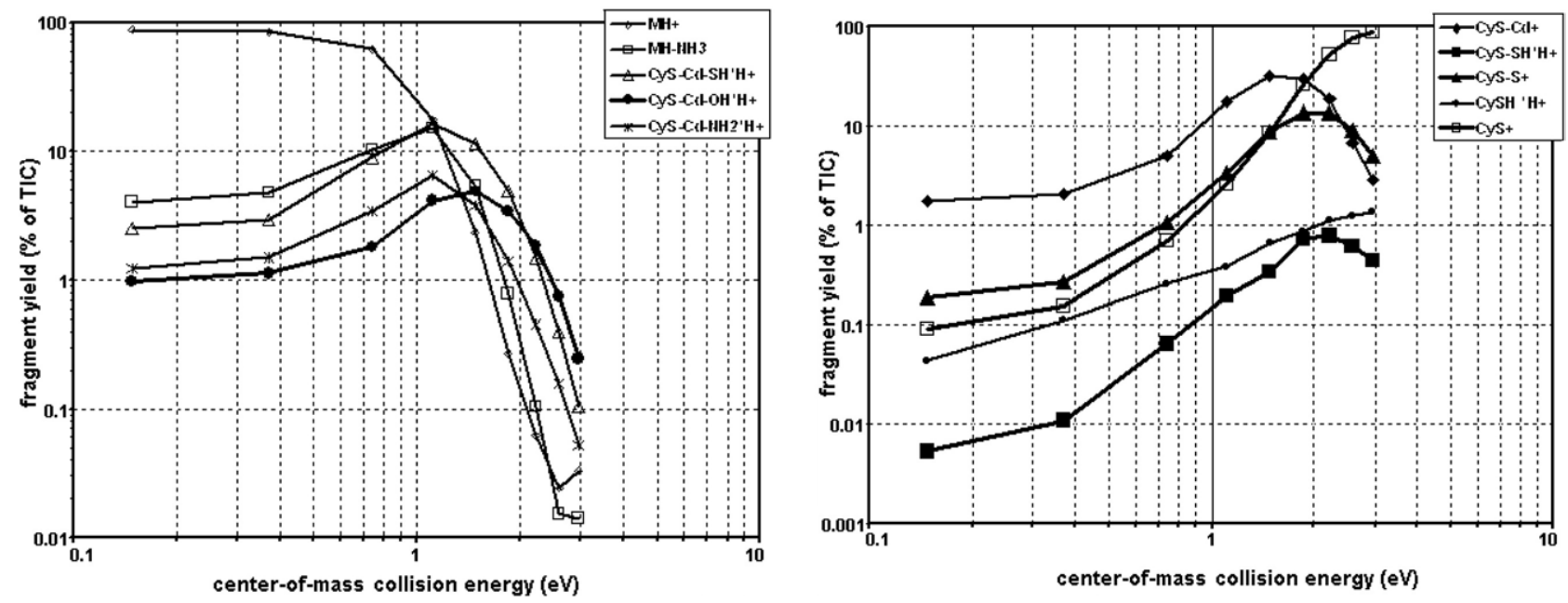

Figure 6. Fragment yield curves for protonated bis-cysteinyl- ${ }^{110}$ cadmium(II) (1). 
Table 3. Center-of-mass collision energy value $(\mathrm{eV})$ for maximum yield of the fragments of protonated bis-cysteinylcadmium(II) 1

$\begin{array}{lc}{\left[\mathrm{MH}-\mathrm{NH}_{3}\right]^{+}} & 1.23 \\ \mathrm{CyS}-\mathrm{Cd}-\mathrm{NH}_{2} * \mathrm{H}^{+} & 1.30 \\ \mathrm{CyS}-\mathrm{Cd}-\mathrm{SH}^{*} \mathrm{H}^{+} & 1.33 \\ \mathrm{CyS}-\mathrm{Cd}-\mathrm{OH}^{*} \mathrm{H}^{+} & 1.59 \\ \mathrm{CyS}-\mathrm{Cd}^{+} & 1.81 \\ \mathrm{CyS}^{+} & 2.18 \\ \mathrm{CyS}^{+} \mathrm{SH}^{*} \mathrm{H}^{+} & 2.30 \\ \mathrm{CyS}^{+} & >3\end{array}$

sponding fragments of the cadmium conjugate of cysteine methyl ester 6 (not reported) show more prominent formation of the $\mathrm{MeOCyS}^{+}$fragment at all collision energy values in the examined range and the intensity of the MeOCyS-Cd ${ }^{+}$fragment starts to decrease at least $0.5 \mathrm{eV}$ earlier than in the free acid $\mathbf{1}$, thus suggesting that the free carboxyl group may have a substantial role in stabilizing the formal mono-positive charge on the metal. This phenomenon is likely to influence the net charge of the conjugate and thus its transport across biological boundaries and therefore deserves a more quantitative investigation, which may prove of great value in unveiling the mechanism of cadmium toxicity at the molecular level. However, the use of energy-resolved mass spectrometric data to study such aspects at the boundary of mass spectrometry and the biological sciences needs a much more accurate control of the experimental conditions of fragment ion analysis for the measurement of threshold energies for fragment ion formation, as repeatedly warned by Armentrout [29].

\section{Discussion and Conclusions}

Several homo- and heterodimeric cadmium(II)-bis-thiolates can be obtained by mixing nearly neutral aqueous solutions of amino acids and peptides and $\mathrm{Cd}(\mathrm{II})$ ions at millimolar concentrations, i.e., at the concentration of intracellular red blood cell glutathione and of plasma amino acids in humans. The obtained abundance of the amino acid-thiol conjugates observed by electrospray ionization is much less than that observed under similar conditions for the corresponding mercury(II) conjugates [21], thus pointing to a lower affinity of cadmium for the thiolate ligand. Although a detailed analysis of these results is beyond the scope of this particular paper, it is conceivable that such differences may underscore those in reactivity, in lipophilicity, in proton affinity, and in other chemical characteristics, which in turn affect toxicokinetic and toxicodynamic differences among the two metals.

Our results are similar to those of recent experiments by Burford and coworkers, who show formation of multiple ionic species of different stoichiometry in the electrospray spectra of cysteine, homo-cysteine and glutathione with several heavy metals among which cadmium and mercury. In particular, they report formation of a cadmium:amino acid ionic species with a
1:2 stoichiometric ratio with cysteine, but not with homo-cysteine [18], thus confirming our difficulty of detecting metal-thiolate conjugates of this amino acid. Also, they are able to obtain mono-S-glutathionyl-cadmium(II) but not the corresponding homodimeric conjugate [19]. It is even worth noting that Rabenstein and coworkers [30] were able to observe differences among some examined thiols in their ability to release cadmium from its glutathione-bound form in human erythrocytes, cysteine being more effective than $N$-acetylcysteine. Differences in the experimental conditions employed for sample preparation and for mass spectrometric analysis (e.g., the use of a heated capillary for electrospray in the employed ion trap mass spectrometer) may explain some of the observed discrepancies and point to the necessity of performing quantitative measurements of the solution equilibria of metal-thiolate systems by mass spectrometry, to compare with those obtained with other electrochemical [11-13] and spectroscopic techniques [31].

The connectivity and the chemical behavior of the obtained compounds can be investigated with the use of tandem mass spectrometry. The fragment spectra of cadmium(II)-bis-thiolates of amino acids and peptides yield structure-specific ions for the different ligands bound to the metal, which allow their identification in biological samples. Unimolecular decomposition channels are in part similar to those already observed for the mercury(II) analogs, but also feature prominent differences, among which occurrence of intense signals of ions due to $(\mathrm{S} \rightarrow \mathrm{N})$ and $(\mathrm{S} \rightarrow \mathrm{O})$ ligand metathesis, which are related to a higher affinity of cadmium(II) than mercury(II) for ligands different from the thiolate anion, such as the hydroxyl group of the carboxylate function and the amino group of the amino acids.

Last, cadmium(II)-bis-thiolates with glutathione and related compounds have been identified in the body fluids of experimental animal [7-9] and human [30, 31] models and may be investigated as specific metabolites for the biological monitoring of exposure to the different chemical forms of environmental cadmium in humans. A detailed knowledge of the molecular mechanisms underlying the toxic effects of metals requires the speciation of the chemical forms under which they are carried among the different body tissues and organs [32] and knowledge of their reactivity under biologically relevant conditions.

The reported data on the relative ease of formation of the different fragments of bis-cysteinyl-cadmium(II), and especially on the reductive loss of the metal from its thiol conjugate, may be related to the extent of oxidative stress caused in the organism by exposure to cadmium $[33,34]$ and may exemplify the multi-faceted contribution of mass spectrometric techniques [35-38] to research into the mechanistic aspects [34] of cadmium toxicology. This particular aspect, which is of a great interest for the mechanistic interpretation of the toxic behavior of cadmium and of other heavy metals is the subject of our foregoing research. 


\section{References}

1. (a)ATSDR toxicological profile for cadmium US Department of Health and Human Services, 1999; (b) Il'yasova, D.; Schwartz, G. G. Cadmium and renal cancer. Toxicol. Appl. Pharmacol. 2005, 207, 179-186.

2. Mascagni, P.; Consonni, D.; Bregante, G.; Chiappino, G.; Toffoletto, F. Olfactory function in workers exposed to moderate airborne cadmium levels. Neuro. Toxicol. 2003, 24, 717-724.

3. Arvidson, B.; Tjalve, $\mathrm{H}$. Distribution of ${ }^{109} \mathrm{Cd}$ in the nervous system of rats after intravenous injection. J. Environ. Pathol. Toxicol. Oncol. 1985, 6(2), 233-240

4. Arvidson, B.; Tjalve, H. Distribution of ${ }^{109} \mathrm{Cd}$ in the nervous system of rats after intravenous injection. Acta Neuropathol. Berlin 1986, 69(1/2), 111-116.

5. Gottofrey, J.; Tjalve, H. Axonal transport of cadmium in the olfactory nerve of the pike. Pharmacol. Toxicol. 1991 69(4), 242-252.

6. Tjalve, H.; Henriksson, J.; Tallkvist, J.; Larsson, B. S.; Lindquist, N. G. Uptake of manganese and cadmium from the nasal mucosa into the central nervous system via olfactory pathways in rats. Pharmacol. Toxicol. 1996, 79(6), 347-356

7. Tallkvist, J.; Persson, E.; Henriksson, J.; Tjaelve, H. Cadmium-metallothionein interactions in the olfactory pathways of rats and pikes. Toxicol. Sci. 2002, 67, $108-113$.

8. Cherian, M. G.; Vostal, J. J. Biliary excretion of cadmium in rat. I. Dose-dependent biliary excretion and the form of cadmium in the bile. J. Toxicol. Environ. Health 1977, 2(4), 945-954.

9. Katoh, M.: Mizutani, N.; Keino, H.; Kashiwamata, S. A low-molecularweight cadmium-binding substance in human and rat livers and human blood. Toxicol. Appl. Pharmacol. 1984, 73(1), 97-104.

10. Zalups, R. K.; Ahmad, S. Molecular handling of cadmium in transporting epithelia. Toxicol. Appl. Pharmacol. 2003, 186, 163-188.

11. Perrin, D. D.; Watt, A. E. Complex formation of zinc and cadmium with glutathione. Biochim. Biophys. Acta 1971, 230, 96-104.

12. Vilarino, T.; Brandariz, I.; Fiol, S.; Lopez-Fonseca, J.; Sastre de Vicente, M. Complexation of $\mathrm{Cd}^{2+}$ by cysteine at ionic strength of $0.7 \mathrm{M}$ studied by differential pulse polarography. Bull. Soc. Chim. Belges 1993, 102(11/ 12), 699-707.

13. Cruz-Vasquez, B. H.; Diaz-Cruz, J. M.; Arino, C.; Esteban, M.; Tauler, R. Study of $\mathrm{Cd}^{2+}$ complexation by the glutathione fragments Cys-Gly (CG) and $\gamma$-Glu-Cys $(\gamma$-EC) by differential pulse polarography. Analyst 2002, 127(3), 401-406.

14. Birgersson, Bo.; Carter, R. E.; Drakenberg, T. A cadmium-113 NMR study of cadmium-glutathione complexes. J. Mag. Res. 1977, 28(2), 299-302.

15. Fuhr, B. J.; Rabenstein, D. L. Nuclear magnetic resonance studies of the solution chemistry of metal complexes. IX. The binding of cadmium, zinc, lead, and mercury to glutathione. J. Am. Chem. Soc. 1973, 95(21), $6944-6950$

16. Li, Z.-S.; Lu, Y.-P.; Zhen, R.-G.; Szczypka, M.; Thiele, D. J.; Rea, P. A. A new pathway for vacuolar cadmium sequestration in Saccharomyces cerevisiae: YCF1-catalyzed transport of bis(glutathione)cadmium. Proc Nat Acad. Sci. U.S.A. 1997, 94(1), 42-47.

17. (a)Yen, T.-Y.; Villa, J. A.; DeWitt, J. Analysis of phytochelatin-cadmium complexes from plant tissue culture using nano-electrospray ionization tandem mass spectrometry and capillary liquid chromatography/electrospray ionization tandem mass spectrometry. J. Mass Spectrom. 1999 34(9), 930-941; (b) Navaza, A. P.; Montes-Bayon, M.; LeDuc, L. L.; Terry, N.; Sanz-Medel, A. Study of phytochelatins and other related thiols as complexing biomolecules of Ass and Cd in wild type and genetically modified Brassica juncea plants. J. Mass Spectrom. 2006, 41, 323-331.

18. Burford, N.; Eelman, M. D.; LeBlanc, W. G. Identification of complexes involving toxic heavy metals with amino acid ligands by electrospray ionization mass spectrometry. Can. J. Chem. 2004, 82, 1254-1259.

19. Burford, N.; Eelman, M. D.; Groom, C. Identification of complexes containing glutathione with $\mathrm{As}(\mathrm{III}), \mathrm{Sb}(\mathrm{III}), \mathrm{Cd}(\mathrm{II}), \mathrm{Hg}(\mathrm{II}), \mathrm{Tl}(\mathrm{I}), \mathrm{Pb}(\mathrm{II})$, or $\mathrm{Bi}(\mathrm{III})$ by electrospray ionization mass spectrometry. J. Inorg. Biochem. 2005, 99, 1992-1997.

20. Belcastro, M.; Marino, T.; Russo, N.; Toscano, M. Interaction of cysteine with $\mathrm{Cu}^{2+}$ and Group IIb $\left(\mathrm{Zn}^{2+}, \mathrm{Cd}^{2+}, \mathrm{Hg}^{2+}\right)$ metal cations: A theoretical study. I. Mass Spectrom. 2005, 40, 300-306.

21. Rubino, F. M.; Verduci, C.; Giampiccolo, R.; Pulvirenti, S.; Brambilla, G.; Colombi, A. Molecular characterization of homo- and heterodimeric mercury(II)-bis-thiolates of some biologically relevant thiols by electrospray ionization and triple quadrupole tandem mass spectrometry. J. Am. Soc. Mass Spectrom. 2004, 15, 288-300.
22. Busch, K. L.; Glish, S.; McLuckey, S. A. Mass spectrometry/mass spectrometry: Techniques and applications of tandem mass spectrometry. VCH Publications, New York, 1988, p 68.

23. (a) Yalcin, T.; Khouw, C.; Csizamadia, I. J.; Peterson, M. R.; Harrison, A. G. Why are b ions stable in peptide spectra? J. Am. Soc. Mass Spectrom. 1995, 6, 1165-1174; (b) Paizs, B.; Lendvay, G.; Vekey, K.; Suhai, S. Formation of $\mathrm{b}_{2}^{+}$ions from protonated peptides: An ab initio study. Rapid Commun. Mass Spectrom. 1999, 13, 525-533; (c) Reid, G. E.; Simpson. R. J.; O'Hair, R. A. J. Leaving group and gas-phase neighboring group effect in the side chain losses from protonated serine and its derivatives. J. Am. Soc. Mass Spectrom. 2000, 11, 1047-1060.

24. Roepstorff, P.; Fohlmann, J. Proposal for a common nomenclature for sequence ions in mass spectra of peptides. Biomed. Mass Spectrom. 1984, 11(11), 601

25. (a)Bienkowski, T.; Danikiewicz, W. Generation and reactions of substituted phenide anions in an electrospray triple quadrupole mass spectrometer. Rapid Commun. Mass Spectrom. 2003, 17(7), 697-705; (b) Danikiewicz, W.; Bienkowski, T.; Poddebniak, D. Generation and reactions of anionic $\sigma$-adducts of 1,3-dinitrobenzene and 1,3,5-trinitrobenzene with carbanions in a gas phase, using an electrospray ion source as the chemical reactor. I. Am. Soc. Mass Spectrom. 2004, 15(6), 927-933.

26. Tuytten, R.; Lemiere, F.; Van Dongen ,W.; Esmans, E. L.; Witters, E.; Herrebout, W.; Van Der Veken, B.; Dudley, E.; Newton, R. P. Intriguing mass spectrometric behavior of guanosine under low energy collisioninduced dissociation: $\mathrm{H} 2 \mathrm{O}$ adduct formation and gas-phase reactions in the collision cell. J. Am. Soc. Mass Spectrom. 2005, 16(8), 1291-1304. (Erratum 2005, 16(11), 1904.)

27. (a)Rogalewicz, F.; Hoppiliard, Y.; Ohannessian, G. Fragmentation mechanism of $\alpha$-amino acids protonated under electrospray ionization: A collisional activation and ab initio theoretical study. Int. J. Mass Spectrom. 2000, 195/196, 565-590; (b) O'Hair, R. A. J.; Styles, M. L.; Reid, $\mathrm{G}$. E. Role of the sulfhydryl group on the gas-phase fragmentation reactions of protonated cysteine and cysteine containing peptides. J. Am. Soc. Mass Spectrom. 1998, 9, 1275-1284; (c) Dookeran, N. N.; Yalcin, T.; Harrison, A. G. Fragmentation reactions of protonated $\alpha$-amino acids. J. Mass Spectrom. 1996, 31(5), 500-508.

28. Rubino, F. M.; Verduci, C.; Giampiccolo, R.; Pulvirenti, S.; Brambilla, G.; Colombi, A. Characterization of the disulfides of biothiols by electrospray ionization and triple-quadrupole tandem mass spectrometry. $J$. Mass Spectrom. 2004, 39, 1408-1416.

29. (a)Rodgers, M. T.; Armentrout, P. B. Noncovalent metal-ligand bond energies as studied by threshold collision-induced dissociation. Mass Spectrom. Rev. 2000, 19, 215-247; (b) Armentrout, P. B. Kinetic energy dependence of ion-molecule reactions: Guided ion beams and threshold measurements. Int. J. Mass Spectrom. 2000, 200, 219-241; (c) Armentrout, P. B. Mass spectrometry-not just a structural tool: The use of guided ion beam tandem mass spectrometry to determine thermochemistry. J. Am. Soc. Mass Spectrom. 2002, 13, 419-434.

30. Rabenstein, D. L.; Isab, A. A.; Kadima, W.; Mohanakrishnan, P. A PMR study of the interaction of cadmium with human erythrocytes. Biochim. Biophys. Acta 1983, 762, 531-541.

31. Kadima, W.; Rabenstein, D. L. A quantitative study of the complexation of cadmium in hemolyzed human erythrocytes by 1NMR spectroscopy. J. Inorg. Biochem. 1990, 40, 141-149.

32. Fante, H.; Fernandez-Sanchez, M. L.; Sanz-Medel, A. Cadmium-bound species in human urine using HPLC-vesicular hydride generation ICPMS. J. Anal. Atom. Spectrosc. 1999, 14, 1343-1348.

33. Stohs, S. J.; Bagchi, D.; Hassoun, E.; Bagchi, M. Oxidative mechanisms in the toxicity of chromium and cadmium ions. J. Environ. Pathol. Toxicol. Oncol. 2000, 19(3), 201-213.

34. Wang, Y.; Fang, J.; Leonard, S. S.; Krishna-Rao, K. M. Cadmium inhibits the electron transfer chain and induces reactive oxygen species. Free Radical Biol. Med. 2004, 36(11), 1434-1443.

35. Shindo, M.; Irie, K.; Fukuda, H.; Ohigashi, H. Analysis of the noncovalent interaction between metal ions and the cysteine-rich domain of protein kinase $\mathrm{C} \eta$ by electrospray ionization mass spectrometry. Bioorg. Med. Chem. 2003, 11, 5075-5082.

36. Nesatyy, V.; Rutishauser, B. V.; Eggen, R. I. L.; Suter, M. J. F. Identification of the estrogen receptor Cd-binding sites by chemical modification. Analyst 2005, 130, 1087-1097.

37. Larabee, J. L.; Hocker, J. R.; Hanas, J. S. Cys redox reactions and metal binding of a $\mathrm{Cys}_{2} \mathrm{His}_{2}$ zinc finger. Arch. Biochem. Biophys. 2005, 434, 139-149.

38. Marino, T.; Russo, N.; Toscano, M. A comparative study of the catalytic mechanisms of the zinc and cadmium containing carbonic anhydrase. J. Am. Chem. Soc. 2005, 127, 4242-4253. 